\title{
An Eulerian Approach to the \\ Large Displacement Analysis of Thin-Walled Frames
}

\author{
B.A. Izzuddin*
}

\section{ABSTRACT}

This paper presents a new approach for the geometrically nonlinear analysis of thin-walled space frames. The proposed approach employs an Eulerian (convected) system for the definition of local element freedoms, and is capable of representing the effects of large displacements, finite rotations and cross-sectional warping. The use of the Eulerian system has been shown to be advantageous in the context of adaptive elasto-plastic analysis, and the particular approach adopted has demonstrated a high level of accuracy which is quite insensitive to the size of the incremental load step. An important feature of the new approach is the separation of the transformations concerned with the effects of large displacements and finite rotations from the details of the element formulation, which allows the proposed approach to accommodate formulations of various degrees of sophistication. To demonstrate the accuracy of the new approach, a simple, yet powerful, finite element formulation is presented, which is capable of modelling thin-walled members with any open cross-sectional shape. Whilst such formulation is linear in the local system, its incorporation within the large displacement Eulerian approach allows geometrically nonlinear effects, such as lateral torsional buckling, to be accurately modelled. The incorporation of the local element response within a global nonlinear analysis capability based on the Eulerian approach is discussed, and essential requirements related to the coupling of warping freedoms of adjacent elements are outlined. Verification examples using ADAPTIC are finally presented to demonstrate the accuracy and efficiency of the proposed approach.

\footnotetext{
${ }^{*}$ Lecturer in Engineering Computing, Civil Engineering Department, Imperial College, London SW7 2BU, U.K.
} 


\section{INTRODUCTION}

The prediction of nonlinear structural response is increasingly finding application in design practice, becoming less restricted to research activities. The design of important structures subject to severe loading conditions is just one example where nonlinear analysis tools are proving indispensable, allowing the complex interaction between structural components to be modelled in the range of nonlinear response, which may be due to material inelasticity or geometric effects.

Thin-walled frames represent an important class of structures which cannot be accurately modelled by conventional nonlinear frame analysis tools. This is mainly due to the inability of the underlying methods to account for non-uniform cross-sectional warping, which significantly influences the overall response of such structures, particularly with regard to lateral torsional instability. Whilst advanced shell finite elements can provide an accurate prediction of the nonlinear response of thinwalled members, their two-dimensional nature demands significant modelling and computational efforts. Therefore, the use of this type of elements has been restricted to studying the nonlinear response of individual members, or at best small assemblages, usually as part of parametric research studies.

Over the recent decades, considerable research efforts have been devoted to extending the capabilities of conventional nonlinear frame analysis methods, utilising one-dimensional finite elements, to the domain of thin-walled structures ${ }^{1-9}$. These have been mainly driven by the computational savings and modelling advantages to be derived, since a significant number of twodimensional shell elements could thus be replaced with few one-dimensional elements defined along the member length. In these developments, the key issue has been the integration of the modelling of cross-sectional warping within the nonlinear frame analysis procedures. Whilst earlier research work has been mostly concerned with individual members $1,4,5$, the interaction of thin-walled members within a structural frame has received significant attention, invariably using the Updated Lagrangian approach. In particular, Conci and Gattass 8 and Chen and Blandford ${ }^{9}$ employed such an approach with a cantilever-bound local reference system $^{10}$ to develop one-dimensional nonlinear finite elements for thin-walled I-beams and members with any open cross-section, respectively. 
The present work is concerned with extending an Eulerian approach, previously proposed by the writer ${ }^{11,12}$ for the large displacement analysis of space frames, to the domain of thin-walled structures. The main advantages of the new approach are its high level of accuracy which is quite insensitive to the size of the incremental load step; its ability to readily accommodate elements of various degrees of sophistication; and its natural applicability to adaptive elasto-plastic analysis ${ }^{13,14}$. The latter consideration is particularly important, since adaptive analysis techniques have been shown to provide significant modelling advantages and often more than $80 \%$ of computational savings 14 .

The paper proceeds with outlining the fundamentals of the proposed Eulerian approach, and describing the procedure for incorporating warping effects in the context of large displacement analysis. Distinction is made between the transformation details required for large displacement analysis and the details of element formulation, thus allowing the proposed approach to readily accommodate various types of formulation. To illustrate the advantages of the Eulerian approach, a simple, yet powerful, Eulerian formulation is described, which is capable of modelling thin-walled members with any open cross-section. Verification and application examples, using the nonlinear analysis program ADAPTIC 15 , are finally presented to demonstrate the accuracy and efficiency of the proposed approach. Particular consideration is given to the nonlinear response of thin-walled frames subject to lateral torsional instability, and comparisons are made where possible with the results of other theoretical and numerical approaches.

\section{BACKGROUND}

Nonlinear structural analysis is mainly concerned with establishing the structural deformed shape, hence strains and stresses, under equilibrium conditions and at various loading levels. In the context of finite element analysis, the displacements $U$ corresponding to a finite set of freedoms are obtained by solving a nonlinear system of equilibrium equations, given by:

$P_{j}=\sum_{e}{ }_{g}^{e} f_{j} \quad$ for $j=1, n$

where, 
$P_{j} \quad$ : global applied/equivalent load at freedom $(\mathrm{j})$,

${ }_{g} f_{j} \quad$ : global resistance force of element (e) corresponding to freedom (j), and

n : total number of global freedoms.

For thin-walled frames, the displacements vector $U$ includes translational, rotational as well as warping freedoms. The applied load $\mathrm{P}$ can include forces as well as moments, although the nature of global moments depends on the adopted definition for rotational freedoms ${ }^{12}$. It can also be shown that the global element forces vector ${ }_{\mathrm{g}}^{\mathrm{e}} \mathrm{f}$ represents the first derivatives of the element strain energy ${ }^{\mathrm{e}} \mathrm{U}$ with respect to global displacements ${ }^{12}$, as given by:

${ }_{\mathrm{g}}^{\mathrm{e}} \mathrm{f}_{\mathrm{j}}=\frac{\partial\left({ }^{\mathrm{e}} \mathrm{U}\right)}{\partial \mathbf{U}_{\mathrm{j}}}$

The formulation of the element strain energy ${ }^{\mathrm{e}} \mathrm{U}$ in terms of the global displacements $U$ becomes too complex in the context of large displacement analysis, and hence a local system is often introduced. Such a system utilises a set of local element freedoms ${ }_{\mathrm{c}} \mathrm{u}$, which can be used to define the element strain energy, allowing the global element forces in (2) to be expressed as:

${ }_{\mathrm{g}}^{\mathrm{e}} \mathrm{f}_{\mathrm{j}}=\sum_{\mathrm{i}}\left(\frac{\partial_{\mathrm{c}} \mathrm{u}_{\mathrm{i}}}{\partial \mathrm{U}_{\mathrm{j}}} \frac{\partial\left({ }^{\mathrm{e}} \mathrm{U}\right)}{\partial_{\mathrm{c}} \mathrm{u}_{\mathrm{i}}}\right)$

or,

${ }_{\mathrm{g}}^{\mathrm{e}} \mathrm{f}_{\mathrm{j}}=\sum_{\mathrm{i}} \mathrm{T}_{\mathrm{j}, \mathrm{i}} \mathrm{c}^{\mathrm{f}} \mathrm{i}_{\mathrm{i}}$

where,

$\mathrm{T} \quad$ : transformation matrix between the local and global systems, and

$\mathrm{c}_{\mathrm{i}} \quad$ : local element force corresponding to local freedom (i).

Equation (3.b) depicts the separation of the large displacement transformations, represented by $\mathrm{T}$, from the details of the element response in the local system, represented by ${ }_{c} f$, which allows the large displacement approach to be utilised with elements of various degrees of accuracy and 
sophistication. The next section outlines the Eulerian approach proposed for the large displacement analysis of thin-walled frames, presenting the relationship between local displacements ${ }_{\mathrm{c}} \mathrm{u}$ and global displacements $U$, thereby allowing the determination of the transformation matrix $T$. The proceeding section describes a formulation for thin-walled members which is capable of modelling any open cross-sectional shape, utilising the Eulerian system for deriving the local element forces ${ }_{\mathrm{c}}^{\mathrm{f}}$. Although the proposed formulation is linear in the local system, its incorporation within the large displacement Eulerian approach allows geometrically nonlinear effects, such as lateral torsional instability, to be accurately modelled.

\section{EULERIAN SYSTEM}

The Eulerian system is a local convected system which follows the element chord during deformation, as shown in Fig. 1. This effectively isolates strain-inducing deformation states from stress-free rigid body states, which proves to be quite convenient in formulating the details of the local element response, as demonstrated in the following section.

In the context of finite element analysis, global degrees of freedom are used to ensure compatibility of displacements between adjacent elements and to enforce support boundary conditions. In order to account for finite rotations, an incremental definition of global displacements is utilised herein. Each element has 12 basic global degrees of freedom ${ }_{\mathrm{g}}^{\mathrm{b}} \mathrm{u}$, corresponding to incremental rotational and translational displacements at the two element nodes in the three global directions. Moreover, to ensure compatibility of warping displacements between adjacent elements modelling the same thinwalled member, 2 additional warping freedoms ${ }_{\mathrm{g}}^{\mathrm{w}} \mathrm{u}$ are utilised. Hence, the incremental element global displacements vector ${ }_{\mathrm{g}} \mathrm{u}$ includes 14 degrees of freedom (Fig. 1), as expressed in partitioned form by:

$$
\mathrm{g} u=\left\{\begin{array}{c}
\mathrm{b} \\
\mathrm{g} \\
\mathrm{w}_{\mathrm{g}} \mathrm{u} \\
\mathrm{g}
\end{array}\right\}=\left\{\begin{array}{llllllllllllll}
\mathrm{u}_{1} & \mathrm{v}_{1} & \mathrm{w}_{1} & \alpha_{1} & \beta_{1} & \gamma_{1} & \mathrm{u}_{2} & \mathrm{v}_{2} & \mathrm{w}_{2} & \alpha_{2} & \beta_{2} & \gamma_{2} ! & \chi_{1} & \chi_{2}
\end{array}\right\}^{\mathrm{T}}
$$

The warping freedoms $\left(\chi_{1}, \chi_{2}\right)$ are first derivatives of the twist rotation with respect to the local $\mathrm{x}$ axis, and hence they are displayed in Fig. 1 in the local system. However, $\left(\chi_{1}, \chi_{2}\right)$ are included in the 
global displacements vector ${ }_{\mathrm{g}} \mathrm{u}$ since they are directly used to enforce cross-sectional warping compatibility between adjacent elements, as discussed in more detail later.

In the local Eulerian system, an element utilises 8 degrees of freedom ${ }_{\mathrm{c}} \mathrm{u}$, as shown in Fig. 2, which are expressed in total, rather than incremental, form. These include the 6 basic degrees of freedom ${ }_{\mathrm{c}}^{\mathrm{b}}$ and 2 additional warping freedoms ${ }_{\mathrm{c}}^{\mathrm{w}} \mathrm{u}$, as given in partitioned form by:

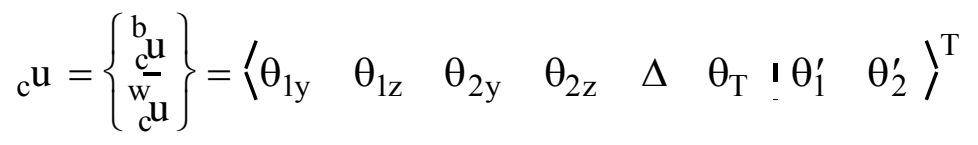

For a given set of global element displacements ${ }_{\mathrm{g}} \mathrm{u}$, the increment of local basic displacements $\delta_{\mathrm{c}}^{\mathrm{b}} \mathrm{u}$ is determined from ${ }_{\mathrm{g}}^{\mathrm{b}} \mathrm{u}$ as proposed previously by the writer ${ }^{11,12}$, which accounts for large displacements and finite rotations. The increment of local warping displacement $\delta_{\mathrm{c}}^{\mathrm{w}} \mathrm{u}$, representing the remaining part of the incremental local displacements $\delta_{\mathrm{c}} \mathrm{u}$, is identical to ${ }_{\mathrm{g}}^{\mathrm{w}} \mathrm{u}$, as expressed by:

$\delta_{\mathrm{c}}^{\mathrm{W}} \mathrm{u}={ }_{\mathrm{g}}^{\mathrm{w}} \mathrm{u}$

Once $\delta_{\mathrm{c}} \mathrm{u}$ has been determined for a given ${ }_{\mathrm{g}} \mathrm{u}$, the total local displacements ${ }_{\mathrm{c}} \mathrm{u}$ are established incrementally from the previous equilibrium step:

$$
\begin{aligned}
& \delta_{\mathrm{c}} \mathrm{u}=\left\{\begin{array}{l}
\delta_{\mathrm{c}}^{\mathrm{b}} \mathrm{u} \\
\delta_{{ }_{\mathrm{c}}}^{\mathrm{w}}
\end{array}\right\} \\
& { }_{\mathrm{c}}^{\mathrm{u}}={ }_{\mathrm{c}} \mathrm{u}^{\mathrm{o}}+\delta_{\mathrm{c}} \mathrm{u}
\end{aligned}
$$

where,

${ }_{\mathrm{c}^{\mathrm{u}}} \mathrm{o}^{\mathrm{a}}$ : local element displacements at the end of the last equilibrium step.

The local element response is thereafter obtained for the current local displacements ${ }_{c} \mathrm{u}$, as discussed in the following section. 


\section{ELEMENT RESPONSE}

In the context of the proposed Eulerian approach, the accuracy and applicability of formulations depends primarily on the details of the element response in the local system. Several formulations, differing in applicability and complexity, have been proposed by the writer for large displacement analysis of thin-walled frames; notably, a linear elastic formulation for members having an Isection $^{16}$, a nonlinear elastic formulation for representing a whole member using only one element ${ }^{17}$, and an elasto-plastic formulation employing a yield criterion based on direct strains ${ }^{18}$.

The previous elastic formulation ${ }^{16}$ is extended herein to model thin-walled members with any open cross-section, as discussed hereafter. Although such a formulation is linear in the local system, its incorporation within the large displacement Eulerian approach allows geometric nonlinearity effects, including lateral torsional instability, to be accurately modelled, as shown in the examples section of this paper.

\subsection{Kinematics}

The proposed formulation utilises the displacements along a one-dimensional reference line to define the stresses and strains at all material points. These displacements include three translations and one twist rotation, $\mathrm{u}_{\mathrm{g}}(\mathrm{x}), \mathrm{v}_{\mathrm{g}}(\mathrm{x}), \mathrm{w}_{\mathrm{g}}(\mathrm{x})$ and $\alpha_{\mathrm{g}}(\mathrm{x})$, as shown in Fig. 3. The displacements of material points within a general open cross-section, such as shown in Fig. 4, can be expressed in terms of the reference line displacements by:

$$
\begin{aligned}
& \mathrm{u}=\mathrm{u}_{\mathrm{g}}-\frac{\mathrm{dv}_{\mathrm{g}}}{\mathrm{dx}} \mathrm{y}-\frac{\mathrm{dw_{ \textrm {g } }}}{\mathrm{dx}} \mathrm{z}+\frac{\mathrm{d} \alpha_{\mathrm{g}}}{\mathrm{dx}} \Phi(\mathrm{y}, \mathrm{z}) \\
& \mathrm{v}=\mathrm{v}_{\mathrm{g}}-\alpha_{\mathrm{g}} \mathrm{z} \\
& \mathrm{w}=\mathrm{w}_{\mathrm{g}}+\alpha_{\mathrm{g}} \mathrm{y}
\end{aligned}
$$

Expression (8.a) is based on the assumption that plane sections remain plane and normal to the reference line in the absence of cross-sectional warping, with displacements due to warping being dependent on the rate of twist and a warping function $\Phi(\mathrm{y}, \mathrm{z})$ defined by the cross-sectional shape. 
Expressions (8.b) and (8.c) merely relate the cross-sectional transverse displacements to those of the reference line and the rotational twist, assuming small rotations.

One important consideration, affecting the choice of the reference line and the warping function, is that the average axial displacement $(\mathrm{u})$ over a cross-section should be independent of the derivatives of $\mathrm{v}_{\mathrm{g}}(\mathrm{x}), \mathrm{w}_{\mathrm{g}}(\mathrm{x})$ and $\alpha_{\mathrm{g}}(\mathrm{x})$. Otherwise, the average axial strain over the cross-section would be dependent on bending and torsional curvatures, leading to non-zero values for the axial force under pure bending or torsional loading when using a displacement-based finite element approach. This can be avoided if the following conditions, obtained from (8.a), are satisfied:

$$
\begin{aligned}
& \int \mathrm{y} d A=0 \\
& \int \mathrm{z} d A=0 \\
& \int \Phi(y, z) d A=0
\end{aligned}
$$

Conditions (9.a) and (9.b) are readily satisfied by choosing the reference line as coinciding with the centroidal axis of the member. The warping function $\Phi(y, z)$ must satisfy condition (9.c) as well as continuity at the intersections of component plates of the cross-section. Considering two intersecting component plates (i) and (j), such as shown in Fig. 5, the warping function for plate (i), and similarly for plate $(\mathrm{j})$, can be expressed in terms of the local plate coordinates as:

$\Phi_{i}\left(y_{i}, z_{i}\right)=z_{i}^{o} y-y_{i}^{o} z+y_{i} z_{i}+\lambda_{i}$

with,

$y=y_{i}^{o}+\cos \left(\rho_{i}\right) y_{i}-\sin \left(\rho_{i}\right) z_{i}$

$z=z_{i}^{o}+\sin \left(\rho_{i}\right) y_{i}+\cos \left(\rho_{i}\right) z_{i}$

where, 
$\lambda_{\mathrm{i}} \quad$ : warping constant for plate (i).

The above expression for the warping function is derived from the condition that the out-of-plane shear strain in any component plate as well as the in-plane shear strain at the plate mid-thickness are zero. The warping constants $\lambda_{i}$, required for completely defining the warping function, are obtained from equations enforcing the continuity requirement at the intersection of two plates. Considering again plates (i) and (j) in Fig. 5, this requirement is satisfied at the mid-thickness intersection of the two plates if:

$\Phi_{\mathrm{i}}\left(\frac{\mathrm{b}_{\mathrm{i}}}{2}, 0\right)=\Phi_{\mathrm{j}}\left(\frac{-\mathrm{b}_{\mathrm{j}}}{2}, 0\right)$

or using (10),

$\lambda_{i}-\lambda_{j}=\frac{b_{i}}{2}\left(\sin \left(\rho_{i}\right) y_{i}^{o}-\cos \left(\rho_{i}\right) z_{i}^{o}\right)+\frac{b_{j}}{2}\left(\sin \left(\rho_{j}\right) y_{j}^{o}-\cos \left(\rho_{j}\right) z_{j}^{o}\right)$

For a cross-section composed of (n) plates, (n-1) equations can be obtained using (12). One more equation is needed to evaluate all the warping constants, which is directly determined from the requirement (9.c) of a zero average for the cross-sectional warping displacements. Combining (9.c) and (10.a), the required equation is obtained as:

$\sum_{i=1}^{n} b_{i} t_{i} \lambda_{i}=0$

The solution of the previous equations for the warping constants is simplified by establishing $\left(\lambda_{i}, i=2, n\right)$ in terms of $\left(\lambda_{1}\right)$ using (12), and then substituting in (13) to determine $\left(\lambda_{1}\right)$ and, consequently, all the other constants.

Having determined the warping function, the displacements over a cross-section, given by (8), can be established once the reference line displacements, $\mathrm{u}_{\mathrm{g}}(\mathrm{x}), \mathrm{v}_{\mathrm{g}}(\mathrm{x}), \mathrm{w}_{\mathrm{g}}(\mathrm{x})$ and $\alpha_{\mathrm{g}}(\mathrm{x})$, are known. Shape functions are used to interpolate these displacements in terms of the local element freedoms ${ }_{\mathrm{c}} \mathrm{u}$ shown in Fig. 2, in accordance with the displacement-based finite element approach. It is evident from the element boundary conditions that a linear shape function can be used for $u_{g}(x)$, whereas cubic shape functions can be used for $\mathrm{v}_{\mathrm{g}}(\mathrm{x})$ and $\mathrm{w}_{\mathrm{g}}(\mathrm{x})$. Noting that cross-sectional warping is 
related to the rate of twist, the two warping freedoms, $\theta_{1}^{\prime}$ and $\theta_{2}^{\prime}$, represent boundary conditions on the first derivative of the twist rotation $\alpha_{\mathrm{g}}(\mathrm{x})$, and hence a cubic shape function can also be used for $\alpha_{\mathrm{g}}(\mathrm{x})$. Assuming small displacements in the local system, the following shape functions can be derived:

$\mathrm{u}_{\mathrm{g}}(\mathrm{x})=\Delta\left(\frac{\mathrm{x}}{\mathrm{L}}\right)$

$v_{g}(x)=\left(L\left\{\theta_{1 y}+\theta_{2 y}\right\}\left(\frac{x}{L}\right)^{3}-\left(L\left\{\theta_{1 y}+\theta_{2 y}\right\}\left(\frac{x}{L}\right)^{2}+\theta_{1 y} x\right.\right.$

$w_{g}(x)=\left(L\left\{\theta_{1 z}+\theta_{2 z}\right\}\right)\left(\frac{x}{L}\right)^{3}-\left(L\left\{2 \theta_{1 z}+\theta_{2 z}\right\}\right)\left(\frac{x}{L}\right)^{2}+\theta_{1 z} x$

$\alpha_{\mathrm{g}}(\mathrm{x})=\left(\mathrm{L}\left\{\theta_{1}^{\prime}+\theta_{2}^{\prime}\right\}-2 \theta_{\mathrm{T}}\right)\left(\frac{\mathrm{x}}{\mathrm{L}}\right)^{3}-\left(\mathrm{L}\left\{2 \theta_{1}^{\prime}+\theta_{2}^{\prime}\right\}-3 \theta_{\mathrm{T}}\right)\left(\frac{\mathrm{x}}{\mathrm{L}}\right)^{2}+\theta_{1}^{\prime} \mathrm{x}$

It is worth noting that whilst the displacements of this formulation are assumed small in the local system, large global displacements and finite rotations can be accounted for by virtue of its incorporation within the proposed Eulerian approach.

\subsection{Local Forces}

The local element forces ${ }_{c} f$ can be obtained as the first derivatives of the element strain energy with respect to local element displacements ${ }_{\mathrm{c}} \mathrm{u}$ or, equivalently, using the virtual work method. Considering that the only strains allowed for by the present formulation are the cross-sectional strains $\varepsilon_{\mathrm{x}}, \gamma_{\mathrm{xy}}$ and $\gamma_{\mathrm{xz}}$, the virtual work equation becomes:

$c^{f} f_{i}=\int\left(E \varepsilon_{x} \frac{\partial \varepsilon_{x}}{\partial_{c} u_{i}}+G \gamma_{x y} \frac{\partial \gamma_{x y}}{\partial_{c} u_{i}}+G \gamma_{x z} \frac{\partial \gamma_{x z}}{\partial_{c} u_{i}}\right) d A d x$

where from (8),

$\varepsilon_{\mathrm{x}}=\frac{\partial \mathrm{u}}{\partial \mathrm{x}}=\frac{\mathrm{du} \mathrm{g}}{\mathrm{dx}}-\frac{\mathrm{d}^{2} \mathrm{v}_{\mathrm{g}}}{\mathrm{dx}^{2}} \mathrm{y}-\frac{\mathrm{d}^{2} \mathrm{w}_{\mathrm{g}}}{\mathrm{dx}^{2}} \mathrm{z}+\frac{\mathrm{d}^{2} \alpha_{\mathrm{g}}}{\mathrm{dx}^{2}} \Phi(\mathrm{y}, \mathrm{z})$ 
$\gamma_{x y}=\frac{\partial u}{\partial y}+\frac{\partial v}{\partial x}=\frac{d \alpha_{g}}{d x}\left(\frac{\partial \Phi}{\partial y}-z\right)$

$\gamma_{\mathrm{xz}}=\frac{\partial \mathrm{u}}{\partial \mathrm{z}}+\frac{\partial \mathrm{w}}{\partial \mathrm{x}}=\frac{\mathrm{d} \alpha_{\mathrm{g}}}{\mathrm{dx}}\left(\frac{\partial \Phi}{\partial \mathrm{z}}+\mathrm{y}\right)$

Note that first order approximation of the strains is employed in the previous expressions, and hence this formulation is linear in the local system and cannot model the Wagner effect ${ }^{19}$, as discussed in the following section.

Combining equations (14), (15) and (16), the following explicit expression for the local element forces can be obtained:

$\mathrm{c}^{\mathrm{f}} \mathrm{i}=\sum_{\mathrm{j}=1}^{8} \mathrm{c}_{\mathrm{i}, \mathrm{j}} \mathrm{c}^{\mathrm{u}}$

or in partitioned form, separating warping from basic freedoms,

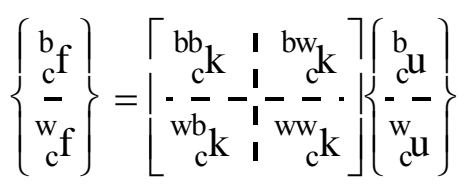

where,

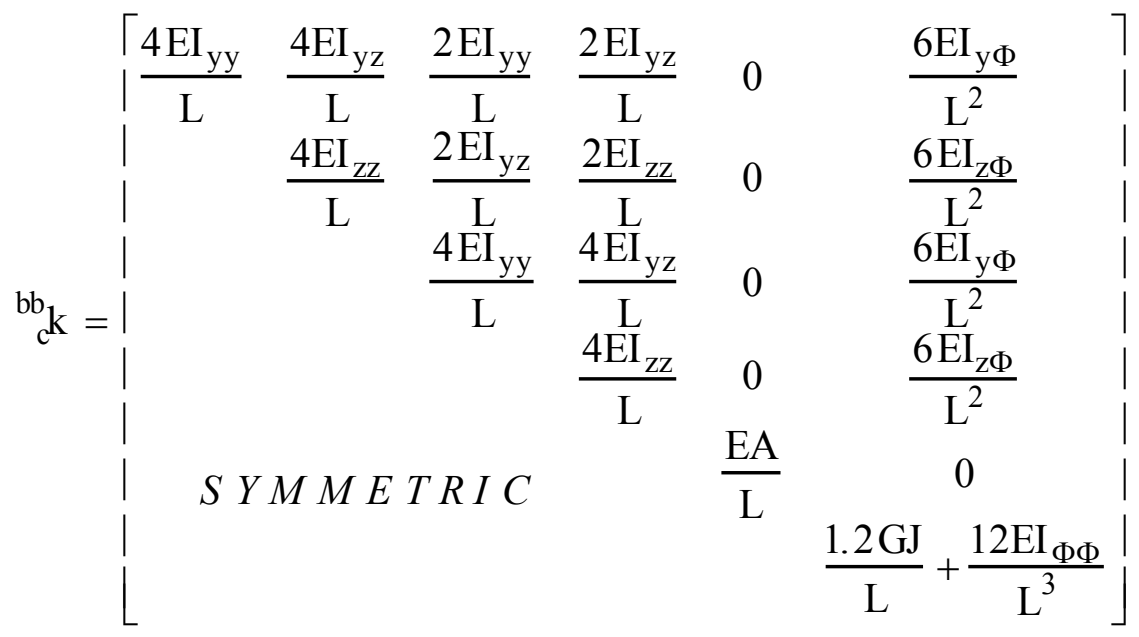




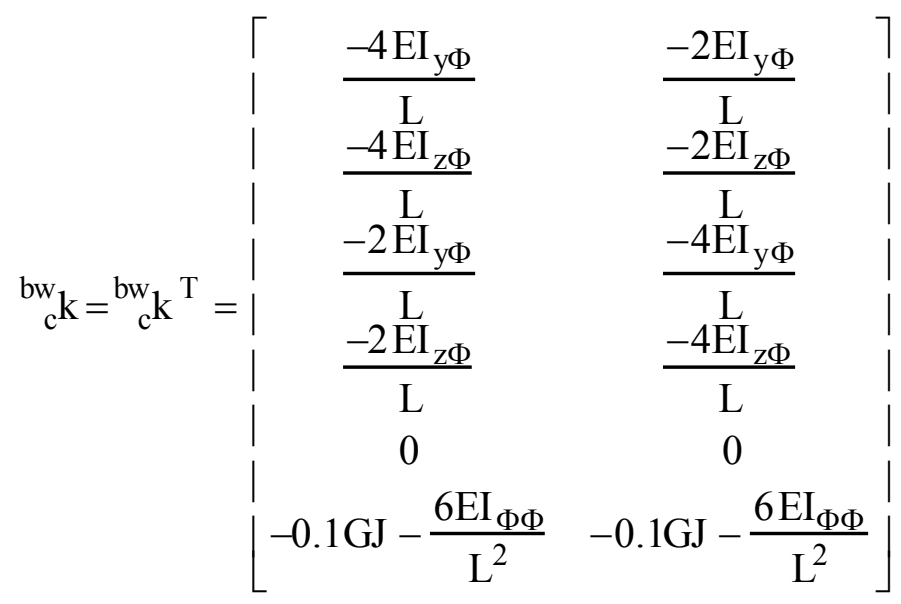

$\mathrm{ww}_{\mathrm{c}}=\left\{\begin{array}{cc}\frac{0.4 \mathrm{GJL}}{3}+\frac{4 \mathrm{EI}_{\Phi \Phi}}{\mathrm{L}} & \frac{-0.1 \mathrm{GJL}}{3}+\frac{2 \mathrm{EI}_{\Phi \Phi}}{\mathrm{L}} \\ \text { SYMMETRIC } & \frac{0.4 \mathrm{GJL}}{3}+\frac{4 \mathrm{EI}_{\Phi \Phi}}{\mathrm{L}}\end{array}\right]$

The cross-sectional constants used in the above expressions for the local stiffness matrix $\mathrm{c}^{\mathrm{k}}$ are defined as follows:

$$
\begin{aligned}
& A=\int d A \\
& I_{y y}=\int y^{2} d A
\end{aligned}
$$

$I_{y z}=\int y z d A$

$$
\mathrm{I}_{\mathrm{y} \Phi}=\int \mathrm{y} \Phi \mathrm{dA}
$$

$I_{z z}=\int z^{2} d A$

$$
\mathrm{I}_{\mathrm{z} \Phi}=\int \mathrm{z} \Phi \mathrm{dA}
$$


$\mathrm{I}_{\Phi \Phi}=\int \Phi^{2} \mathrm{dA}$

$J=\sum_{i=1}^{n} \int 4 z_{i}^{2} \mathrm{dA}_{\mathrm{i}}$

Explicit expressions for the above constants for a general thin-walled open cross-section are given in Appendix A.1.

\subsection{Warping Deformations}

The choice of the centroidal axes as the reference line for the cubic element leads to considerable simplification in the element formulation. However, centroidal formulations have distinctive behavioural characteristics, particularly in relation to the warping of asymmetric open cross-sections.

Considering a channel section as an example asymmetric cross-section, the warping deformations for a centroidal formulation can be verified using (10) to be distributed over the cross-section as shown in Fig. 6.a. If, on the other hand, the origin of the warping freedom is taken outside the channel web, for example at the shear centre, the warping deformations would be distributed as in Fig. 6.b. However, such deformations can be represented by the centroidal cubic formulation, since they are a combination of the warping deformations in Fig. 6.a with a cross-sectional rotation about the y-axis. Hence, centroidal and shear centre formulations have in most situations equivalent response characteristics, although they utilise different freedoms.

There are some differences between the two types of formulation, with shear centre formulations having a disadvantage related to the connectivity of elements being enforced outside the asymmetric cross-section domain. This could lead to spurious situations especially for elements meeting at an angle.

Another important difference is related to warping releases in the presence of rotational restraints or moments. Considering an element having a channel cross-section, with one of the element nodes restrained against all displacements and rotations except for the warping freedom. Clearly, the only 
cross-sectional deformations allowed by centroidal formulations are the warping deformations of Fig. 6.a, while shear centre formulations would only allow the deformations shown in Fig. 6.b. Although this leads to different response predictions by the two types of formulation, such a situation is not believed to be realistic, since it would be difficult in practice to have a system of forces which provides rotational restraints whilst not resisting the two aforementioned warping modes.

\section{GLOBAL ANALYSIS}

The two main requirements for a nonlinear structural analysis capability are (i) the ability to establish and assemble the global element resistance forces, i.e. the right-hand side of (1), given an increment of global displacements $U$, and (ii) the formulation of a global tangent stiffness matrix which can be used within an incremental iterative approach, such as the Newton-Raphson procedure. These are discussed hereafter in the context of the proposed Eulerian approach for large displacement analysis of thin-walled frames, highlighting a number of important considerations particularly in relation to global warping freedoms.

\subsection{Global Forces}

The vector of incremental global element displacements ${ }_{\mathrm{g}} \mathrm{u}$ represents a subset of the incremental structural displacements $U$, from which the local element displacements ${ }_{c} \mathrm{u}$ can be obtained in accordance with Section 4. The local element forces ${ }_{\mathrm{c}} \mathrm{f}$ corresponding to ${ }_{\mathrm{c}} \mathrm{u}$ can be readily established, as given explicitly in Section 5.2 for the elastic cubic formulation. To determine the element contribution to global resistance forces ${ }_{\mathrm{g}}^{\mathrm{e}} \mathrm{f}$, the following transformation is applied to $\mathrm{f}$ :

${ }_{\mathrm{g}}^{\mathrm{e}} \mathrm{f}_{\mathrm{j}}=\sum_{\mathrm{i}=1}^{8} \mathrm{~T}_{\mathrm{j}, \mathrm{i}} \mathrm{c}_{\mathrm{i}} \mathrm{f}_{\mathrm{i}}$

where applying (3) on the element level:

$$
\mathrm{T}_{\mathrm{j}, \mathrm{i}}=\frac{\partial_{\mathrm{c}} \mathrm{u}_{\mathrm{i}}}{\partial_{\mathrm{g}} \mathrm{u}_{\mathrm{j}}}
$$


The transformation matrix $\mathrm{T}$ can be expressed in partitioned form, separating the warping and basic element freedoms, as follows:

$$
\mathrm{T}=\left[\begin{array}{c:c}
{ }^{\mathrm{bb}} \mathrm{T} & { }^{{ }^{\mathrm{bw}} \mathrm{T}} \\
\hdashline{ }^{\mathrm{wb}} \mathrm{T} & { }^{\mathrm{ww}} \mathrm{T}
\end{array}\right]
$$

where,

$$
\begin{aligned}
& { }^{\mathrm{bb}} \mathrm{T}_{\mathrm{j}, \mathrm{i}}=\frac{\partial_{\mathrm{c}}^{\mathrm{b}} \mathrm{u}_{\mathrm{i}}}{\partial_{\mathrm{g}}^{\mathrm{b}} \mathrm{u}_{\mathrm{j}}} \\
& { }^{b w} T_{j, i}=\frac{\partial^{w}{ }_{c} u_{i}}{\partial_{g}^{b} u_{j}} \\
& { }^{w b} T_{j, i}=\frac{\partial_{c}^{b} u_{i}}{\partial_{g}^{w} u_{j}} \\
& { }^{\mathrm{ww}} \mathrm{T}_{\mathrm{j}, \mathrm{i}}=\frac{\partial_{\mathrm{c}}^{\mathrm{w}} \mathrm{u}_{\mathrm{i}}}{\partial_{\mathrm{g}}^{\mathrm{w}} \mathrm{u}_{j}}
\end{aligned}
$$

Matrix ${ }^{\mathrm{bb}} \mathrm{T}$ accounts for the effects of large displacements and finite rotations, and consists of $12 \times 6$ terms which have been previously derived by the writer in an explicit form ${ }^{11,12}$. According to Section $4,{ }^{{ }^{b}} \mathrm{~T}$ and ${ }^{{ }^{b b}} \mathrm{~T}$ are $12 \times 2$ and $2 \times 6$ zero matrices, respectively, whereas ${ }^{{ }^{\mathrm{w}} \mathrm{T}} \mathrm{T}$ is a $2 \times 2$ identity matrix:

$$
{ }^{\mathrm{ww}} \mathrm{T}=\left\lfloor\begin{array}{ll}
1 & 0 \\
0 & 1
\end{array}\right\rfloor
$$

The choice of the element type affects the calculation of the local forces ${ }_{c} f$ corresponding to a set of local displacements ${ }_{\mathrm{c}} \mathrm{u}$; however, the details of the transformation matrix $\mathrm{T}$ and its application according to (19.a) are unaffected, which allows the proposed Eulerian approach to accommodate centroidal or shear centre formulations of various levels of accuracy, applicability and sophistication. Although the elastic cubic formulation presented in the previous section is linear and assumes small displacements in the local Eulerian system, the global element forces obtained from (19.a) are nonlinear with respect to the global increment of displacements, since the effects of large nodal 
displacements and rotations are accounted for. Geometric nonlinearity effects which can be attributed to nodal displacements, such as lateral torsional instability, can be accurately represented by this simple formulation if a sufficient number of elements is used within individual members. However, geometric nonlinearities due to cross-sectional deformation, such as the Wagner effect ${ }^{19}$, require a more involved formulation which is nonlinear in the local Eulerian system, such as the nonlinear elastic quartic formulation proposed by the writer ${ }^{17}$.

\subsection{Global Tangent Stiffness}

The global element tangent stiffness matrix ${ }_{\mathrm{g}} \mathrm{k}$, required for the nonlinear iterative solution procedure, is defined as:

$$
{ }_{g} k_{i, j}=\frac{\partial_{g} f_{i}}{\partial_{g} u_{j}}
$$

Combining (22) with (19), and applying chain differentiation rules, the following expression for ${ }_{\mathrm{g}} \mathrm{k}$ can be obtained:

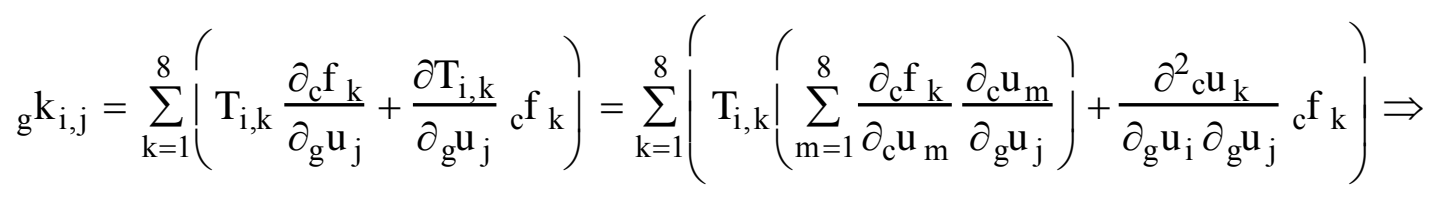

$$
\begin{aligned}
& { }_{\mathrm{g}} \mathrm{k}_{\mathrm{i}, \mathrm{j}}=\sum_{\mathrm{k}=1}^{8}\left(\left(\sum_{\mathrm{m}=1}^{8} \mathrm{~T}_{\mathrm{i}, \mathrm{k}} \mathrm{c}_{\mathrm{k}, \mathrm{m}} \mathrm{T}_{\mathrm{m}, \mathrm{j}}\right)+{ }_{\mathrm{s}} \mathrm{G}_{\mathrm{i}, \mathrm{j}, \mathrm{kc}} \mathrm{f}_{\mathrm{k}}\right)
\end{aligned}
$$

in which,

$$
\begin{aligned}
& \mathrm{c}^{\mathrm{k}_{\mathrm{k}, \mathrm{m}}}=\frac{\partial_{\mathrm{c}^{\mathrm{f}} \mathrm{k}}}{\partial_{\mathrm{c}} \mathrm{u}_{\mathrm{m}}} \\
& { }_{\mathrm{s}} \mathrm{G}_{\mathrm{i}, \mathrm{j}, \mathrm{k}}=\frac{\partial^{2} \mathrm{cu}_{\mathrm{k}}}{\partial_{\mathrm{g}} \mathrm{u}_{\mathrm{i}} \partial_{\mathrm{g}} \mathrm{u}_{\mathrm{j}}}
\end{aligned}
$$

The local tangent stiffness matrix ${ }_{\mathrm{c}} \mathrm{k}$ is dependent on the element type, and is given for the elastic cubic formulation by (17). Array ${ }_{s} \mathrm{G}$ is a $14 \times 14 \times 8$ geometric array governing the effect of the current 
local forces ${ }_{c^{f}}$ on the global tangent stiffness. All terms of ${ }_{s} G$ associated with global and local warping freedoms are zero, as can be readily verified through consideration of (6) and (23.c):

$$
\begin{aligned}
& { }_{s} G_{i, j, 7}={ }_{s} G_{i, j, 8}=0 \quad \forall(i, j) \\
& { }_{s} G_{13, j, k}={ }_{s} G_{14, j, k}={ }_{s} G_{i, 13, k}={ }_{s} G_{i, 14, k}=0 \quad \forall(i, j, k)
\end{aligned}
$$

The other terms of ${ }_{\mathrm{s}} \mathrm{G}$ associated with the basic global and local freedoms have been derived previously by the writer in an explicit form 11,12 .

\subsection{Global Warping Freedoms}

The partitioning of global element matrices, separating terms related to warping and basic freedoms, facilitates the assembly of element contributions into global structural forces and tangent stiffness, particularly since connected elements can share the same basic freedoms at a node whilst having different warping freedoms. For a given mesh of elements, the total number of basic freedoms, prior to accounting for support boundary conditions, is proportional to the number of nodes. However, the total number of warping freedoms depends on whether connected elements have coupled crosssectional warping deformation.

Considering for example the 3-element beam system in Fig. 7.a, compatibility of cross-sectional warping deformation of adjacent elements must be enforced at the connecting nodes. This can be achieved through using one global warping freedom at each nodal position, resulting in a total of 24 basic freedoms and 4 warping freedoms on the global structural level. On the other hand, the 3element system shown in Fig. 7.b utilises the same number of basic freedoms, since the total number of nodes is the same, but requires more warping freedoms. This is due to the fact that the beam elements may warp independently of each other at the connection position, and certainly independently of the column element, thus requiring a total of 6 global warping freedoms.

It is worth noting that coupling the warping freedoms of two members meeting at an angle or having different cross-sections would not ensure compatibility of cross-sectional warping deformations, since warping displacements are in the direction of the element chord and depend on the cross- 
sectional shape, respectively. Although such situations can be simplified by decoupling the warping freedoms and associating free, fully-restrained or intermediate boundary conditions with these freedoms, improved accuracy would be achieved if two-dimensional elements are used to model the connection details. However, significant modelling and computational advantages could still be attained through using one-dimensional elements in the other regions of the structure, with interface elements employed to couple the displacements of one-dimensional and two-dimensional elements within the hybrid mesh.

\section{EXAMPLES}

The proposed Eulerian approach and the cubic formulation have been implemented in the structural analysis program ADAPTIC 15 version v2.3.2, which is a general purpose program for the nonlinear static and dynamic analysis of steel, reinforced concrete and composite frames. Four examples are undertaken using ADAPTIC to demonstrate the accuracy and applicability of the Eulerian approach, in general, and the cubic formulation, in particular.

\subsection{I-Beam}

A simply supported I-beam is restrained against twist at its two ends and is subjected to two equal moments resulting in uniform bending along the beam, as shown in Fig. 8. The applied moments are quasi-tangential ${ }^{20}$, simulated by means of rigid cross-links at the ends, although the nature of the moments has no effects for this example due to the twist restraints.

For the case of free warping at the member ends, the theoretical lateral torsional buckling moment is given by ${ }^{21}$ :

$\mathrm{M}_{\mathrm{cl}}=\frac{\pi}{\mathrm{L}} \sqrt{\frac{\mathrm{EI}_{\mathrm{zz}}\left(\mathrm{GJ}+\mathrm{EI}_{\Phi \Phi} \frac{\pi^{2}}{\mathrm{~L}^{2}}\right)}{\gamma}}$

whereas, for the case of full warping restraint at the member ends, the theoretical lateral torsional buckling moment is given by 22 : 
$\mathrm{M}_{\mathrm{c} 2}=\frac{\pi}{0.883 \mathrm{~L}} \sqrt{\frac{\mathrm{EI}_{\mathrm{zz}}}{\gamma}\left(\mathrm{GJ}+\mathrm{EI}_{\Phi \Phi} \frac{\pi^{2}}{(0.492 \mathrm{~L})^{2}}\right)}$

in which

$\gamma=\left(1-\frac{I_{z z}}{I_{y y}}\right)$

Chwalla's constant $(\gamma)$ accounts for the effect of pre-buckling vertical displacement on the buckling load. Such an effect becomes significant if the second moment of area about the minor axis $I_{z z}$ is significant in comparison with the second moment of area about the major axis $\mathrm{I}_{\mathrm{yy}}$.

The response of the I-beam with free warping at the ends has been studied using three mesh configurations of cubic elements, namely, 2, 4 and 10 elements, where in all cases the symmetric Isection as been modelled with 5 component plates. In order to initiate lateral torsional instability, a quasi-tangential moment of $0.01 \mathrm{M}_{\mathrm{c} 1}$ about the minor axis is initially applied at the right end of the beam, after which the two moments about the major axis are increased proportionally up to and beyond the point of lateral torsional buckling. The results shown in Fig. 9 demonstrate excellent agreement between the buckling moment prediction of the fine mesh of 10 elements and the theoretical solution $\left(\mathrm{M} / \mathrm{M}_{\mathrm{cl}}=1\right)$. It is also evident that two cubic elements, while predicting lateral torsional instability, overestimate the buckling moment by more than $25 \%$. The comparison in Fig. 9 with the results of Conci and Gattass 8 , who used 8 elements based on the Natural Approach, demonstrates the superior performance of the cubic formulation proposed herein. It would appear that Conci and Gattass did not account for Chwalla's constant $(\gamma)$ in their comparisons with the theoretical solution.

For the case of full warping restraint, the results in Fig. 10 demonstrate the accuracy of 10 cubic elements and the reasonable prediction afforded by 4 cubic elements. Here as well, the superior performance of the cubic formulation is illustrated, where the formulation of Conci and Gattass, using 8 elements, underestimates the buckling load by more than $25 \%$. Deflected shapes of the I- 
beam obtained for the case of 10 cubic elements are shown to scale in Figs. 11.a and 11.b, which depict the pre- and post-buckling deflections, respectively.

\subsection{C-Beam}

The thin-walled beam with a circular open cross-section, shown in Fig. 12, has the same support conditions as the previous I-beam with free warping at the member ends, and is subjected to a midspan vertical load applied in the close vicinity of the cross-section shear centre. The cross-section is modelled using 12 straight plate segments, although the cross-sectional properties can be obtained using an analytical expression of the warping function as in Appendix A.2. The beam is modelled using two meshes of 4 and 10 cubic elements, respectively, with the load application at the shear centre achieved by means of a rigid link to the centroidal line.

The C-beam buckles laterally at the theoretical buckling load given by ${ }^{21}$ :

$\mathrm{P}_{\mathrm{c}}=\frac{16.94}{\mathrm{~L}^{2}} \sqrt{\frac{\mathrm{EI}_{\mathrm{zZ}}}{\gamma}\left(\mathrm{GJ}+\mathrm{EI}_{\Phi \Phi} \frac{\pi^{2}}{\mathrm{~L}^{2}}\right)}$,

however, its post-buckling response is asymmetric, characterised by stable and unstable paths depending on the relative position of the load with respect to the shear centre. The stable and unstable post-buckling responses are initiated herein by varying the point of loading within a $0.6 \mathrm{~mm}$ region around the shear centre, with the stable response obtained when the load is closer to the centroid. Results for the vertical and lateral displacements as well as the midside twist, shown in Figs. 13.a and 13.b, provide excellent agreement with the theoretical buckling load $\left(\mathrm{P} / \mathrm{P}_{\mathrm{cr}}=1\right)$, and demonstrate the high accuracy of a coarse mesh of 4 cubic elements. It is worth noting that the buckling load is significantly influenced by the level of eccentricity from the shear centre in the unstable case, with a potential reduction of over $40 \%$. The post-buckling and final deflected shapes for the mesh of 10 cubic elements are shown in Figs. 14.a and 14.b for the unstable case, and in Figs. 15.a and 15.b for the stable case. 


\subsection{L-Frame}

The L-frame in Fig. 16 consists of two members having a channel cross-section with the web lying in the plane of the frame, and with warping restraints imposed at the built-in support and the corner joint. The geometrically nonlinear response of this frame to a concentrated load applied at the shear centre has been investigated by Chen and Blandford ${ }^{9}$ using 8 Updated Lagrangian elements employing a shear centre formulation. For verification purposes, the proposed Eulerian cubic formulation is also used to study this problem, with the element properties corresponding to those given by Ref. [9] as indicated in Fig. 16.

Comparison of the results in Figs. 17.a and 17.b shows that 8 Eulerian cubic elements overestimate the buckling load by $6 \%$, but otherwise provide reasonable agreement with the results of Ref. [9] considering the large displacements involved. The difference between the two sets of results is not a shortcoming of the Eulerian approach, but is mainly attributed to the simplicity of the cubic

formulation which is linear in the local system, and hence cannot model the Wagner effect ${ }^{19}$. Such an effect becomes important for members with an asymmetric cross-section subject to bending about the axis of asymmetry, and for members which are subject to axial forces, the latter being the main consideration for this problem. To illustrate this point, the same problem is analysed using another Eulerian formulation ${ }^{17}$ which employs quartic shape functions for transverse displacements and rotational twist, and which is capable of modelling the nonlinear Wagner effect in the local system. As shown in Figs. 17.a and 17.b, the results using only 4 quartic elements provide excellent agreement with the buckling load prediction of Ref. [9] using 8 elements, thus demonstrating the accuracy of the proposed Eulerian approach. The difference in results at very large displacements may be partly due to the quartic formulation requiring more cross-sectional properties than were provided by Ref. [9].

\subsection{Portal Frame}

The portal frame, depicted in Fig. 18, has an out-of-plane imperfection at its apex of $1 \mathrm{~cm}$ and is assumed to have full warping restraints at the ends of all its members. The response of the portal frame to the shown vertical loading is obtained using 1,2 and 10 cubic elements per member. 
The results shown in Figs. 19.a and 19.b illustrate the applicability of the cubic formulation to global analysis of structures subject to lateral torsional instability and demonstrate the accuracy of the new formulation, which is capable, even with 2 elements per member, of accurately predicting the buckling and post-buckling response of the portal frame. The final deflected shape of the portal frame is shown in Fig. 20.

In order to demonstrate the significance of non-uniform warping for this type of problem, the same portal frame is analysed using Eulerian elements which do not account for warping effects. Each frame member is modelled using two elements, which are identical to the proposed cubic formulation except that they do not utilise warping freedoms and assume uniform warping along the element length. Comparison of the results in Fig. 21 shows that neglecting the warping effects leads to over $80 \%$ reduction in the buckling load, and results in a considerable change in the frame response. This is primarily attributed to the discontinuity in the cross-sectional warping deformation over adjacent elements modelling the same member, as well as the inability to enforce warping restraints at the member ends, as shown in Fig. 22.

\section{CONCLUSIONS}

This paper described a new approach for the large displacement analysis of thin-walled frames. The proposed approach employs an Eulerian (convected) system for modelling large displacement effects as well as geometric nonlinearities which can be associated with nodal displacements. Whilst the Eulerian approach is formulated in such a way to allow the incorporation of various types of formulation, its accuracy and applicability was demonstrated through the use of a simple cubic formulation which was described in detail.

Verification examples using the nonlinear analysis program ADAPTIC showed the applicability of the proposed procedures to the nonlinear analysis of thin-walled members with any open crosssection, and more generally to the analysis of thin-walled frames. The cubic formulation provided excellent prediction of lateral torsional instability effects for members subject to bending about a cross-sectional axis of symmetry, but otherwise, and in the presence of significant axial forces, its 
accuracy diminished since it does not account for the Wagner effect. This was shown to be a shortcoming of the cubic formulation and not the Eulerian approach, which, by virtue of its ability to accommodate more advanced formulations, was proven to model such effects to a high level of accuracy.

The computational and modelling advantages of one-dimensional nonlinear formulations for thinwalled members are significant, especially considering that a frame which can be modelled using few one-dimensional elements would require hundreds of computationally expensive two-dimensional shell elements. In the context of one-dimensional formulations, the Eulerian approach has been shown in previous work to have considerable computational advantages and provide a convenient framework for adaptive elasto-plastic analysis. This has formed the impetus for extending the Eulerian approach to the domain of thin-walled frames, with the next natural step being the development of adaptive analysis techniques for this type of structures. It is not suggested, however, that one-dimensional nonlinear elements would eventually replace two-dimensional shell elements in the analysis of thin-walled frames, since there are complex effects, such as those related to member connections, which are quite difficult to model with one-dimensional elements. It is proposed, nevertheless, that hybrid meshes should be adopted, with one dimensional elements used where applicable to provide modelling and computational efficiency, and two-dimensional elements employed where needed to improve accuracy. Clearly, this would call for the development of nonlinear interface elements which are capable of enforcing continuity requirements between the different element types within the same mesh.

\section{REFERENCES}

1. Trahair N.S. Restrained Elastic Beam-Columns. Journal of the Structural Division, ASCE, 1969, 95, ST12, pp. 2641-2664.

2. Barsoum R.S. and Gallagher R.H. Finite Element Analysis of Torsional and Torsional-Flexural Stability Problems. International Journal for Numerical Methods in Engineering, 1970, 2, pp. $335-352$. 
3. Bazant Z.P. and El-Nimeiri M. Large-Deflection Spatial Buckling of Thin-Walled Beams and Frames. Journal of the Engineering Mechanics Division, ASCE, 1973, 99, EM6, pp. 12591281.

4. Epstein M. and Murray D.W. Three-Dimensional Large Deformation Analysis of Thin-Walled Beams. International Journal of Solids and Structures, 1976, 12, pp. 867-876.

5. Sekulovic M. Geometrically nonlinear analysis of thin-walled members. M.N. Pavlovic (ed.), Steel Structures: recent research advances and their application to design, 1986, Elsevier Applied Science Publishers, London, p.219-243.

6. Yang Y.B. and McGuire W. Stiffness Matrix for Geometric Nonlinear Analysis. Journal of Structural Engineering, ASCE, 1986, 112, No. 4, pp. 853-877.

7. Chan S.L. and Kitipornchai S. Geometric Nonlinear Analysis of Asymmetric Thin-Walled Beam-Columns. Engineering Structures, 1987, 9, pp. 243-254.

8. Conci A. and Gattass M. Natural Coordinates for Geometric Nonlinear Analysis of Thin-Walled Frames. International Journal for Numerical Methods in Engineering, 1990, 30, pp. 207-231.

9. Chen H. and Blandford G.E. Thin-Walled Space Frames. Parts I \& 2. Journal of Structural Engineering, ASCE, 1991, 117, No. 8, pp. 2499-2539.

10. Elias Z.M. Theory and Methods of Structural Analysis. John Wiley and Sons, New York, 1985.

11. Izzuddin B.A. Nonlinear Dynamic Analysis of Space Frames. Thesis Submitted for the Degree of Doctor of Philosophy in the University of London, Department of Civil Engineering, Imperial College, London, 1991.

12. Izzuddin B.A. and Elnashai A.S. Eulerian Formulation for Large Displacement Analysis of Space Frames. Journal of Engineering Mechanics, ASCE, 1993, 119, No. 3, pp. 549-569. 
13. Izzuddin B.A. and Elnashai A.S. Adaptive Space Frame Analysis. Part I: A Plastic Hinge Approach. Proceedings of the Institution of Civil Engineers, Structures and Buildings, 1993, 99, August, pp. 303-316.

14. Izzuddin B.A. and Elnashai A.S. Adaptive Space Frame Analysis. Part II: A Distributed Plasticity Approach. Proceedings of the Institution of Civil Engineers, Structures and Buildings, 1993, 99, August, pp. 317-326.

15. Izzuddin B.A. and Elnashai A.S. ADAPTIC: A Program for the Adaptive Dynamic Analysis of Space Frames, User Manual, 1989, Imperial College, London.

16. Izzuddin B.A. and Lloyd Smith D. A Cubic Eulerian Formulation for Elastic Warping Structures. CIVIL-COMP'93 Conference Proceedings, 1993, The Fifth International Conference on Civil \& Structural Engineering Computing, Edinburgh.

17. Izzuddin B.A. Nonlinear Analysis of Frames Subject to Lateral Torsional Instability. In Structural Dynamics, eds. Moan T. et al, 1993, A.A. Balkema, Rotterdam, pp. 603-608.

18. Izzuddin B.A. and Lloyd Smith D. An Elasto-Plastic Formulation for Thin-Walled Structures. CST'94 Conference Proceedings, 1994, The Second International Conference on Computational Structures Technology, Athens.

19. Goto Y. and Chen W.F. On the Validity of Wagner Hypothesis. International Journal of Solids \& Structures, 1989, 25, No. 6, pp. 621-634.

20. Argyris J.H., Dunne P.C. and Scharpf D.W. On Large Displacement Small Strain Analysis of Structures with Rotational Degrees of Freedom. Computer Methods in Applied Mechanics and Engineering, 1978, (14, pp. 401-451) continued on (15, pp. 99-135).

21. Allen H.G. and Bulson P.S. Background to Buckling. McGraw Hill, Maidenhead, Berkshire, U.K., 1980.

22. Chajes A. Principles of structural stability theory. Prentice-Hall, Englewood Cliffs, N.J., 1974. 


\section{APPENDIX A}

\section{A.1. Properties of General Thin-Walled Cross-Section}

For a general thin-walled cross-section composed on (n) plates, the stiffness constants can be expressed in a summation form over the individual plates, as follows:

$$
\begin{aligned}
& \mathrm{A}=\sum_{\mathrm{i}=1}^{\mathrm{n}} \mathrm{b}_{\mathrm{i}} \mathrm{t}_{\mathrm{i}} \\
& I_{y y}=\sum_{i=1}^{n} \frac{b_{i} t_{i}}{12}\left\{\left(c_{i} b_{i}\right)^{2}+\left(s_{i} t_{i}\right)^{2}+12 y_{i}^{o^{2}}\right\} \\
& I_{y z}=\sum_{i=1}^{n} \frac{b_{i} t_{i}}{12}\left\{c_{i} s_{i}\left(b_{i}^{2}-t_{i}^{2}\right)+12 y_{i}^{o} z_{i}^{o}\right\} \\
& I_{y \Phi}=\sum_{i=1}^{n} \frac{b_{i} t_{i}}{12}\left\{12 \lambda_{i} y_{i}^{o}-c_{i} s_{i} y_{i}^{o}\left(b_{i}^{2}-t_{i}^{2}\right)+z_{i}^{o}\left(\left(c_{i} b_{i}\right)^{2}+\left(s_{i} t_{i}\right)^{2}\right)\right\} \\
& I_{z z}=\sum_{i=1}^{n} \frac{b_{i} t_{i}}{12}\left\{\left(s_{i} b_{i}\right)^{2}+\left(c_{i} t_{i}\right)^{2}+12 z_{i}^{o^{2}}\right\} \\
& I_{z \Phi}=\sum_{i=1}^{n} \frac{b_{i} t_{i}}{12}\left\{12 \lambda_{i} z_{i}^{o}+c_{i} s_{i} z_{i}^{o}\left(b_{i}^{2}-t_{i}^{2}\right)-y_{i}^{o}\left(\left(s_{i} b_{i}\right)^{2}+\left(c_{i} t_{i}\right)^{2}\right)\right\} \\
& \mathrm{I}_{\Phi \Phi}=\sum_{\mathrm{i}=1}^{\mathrm{n}} \frac{\mathrm{b}_{\mathrm{i}} \mathrm{t}_{\mathrm{i}}}{12}\left\{12 \lambda_{\mathrm{i}}{ }^{2}+\mathrm{t}_{\mathrm{i}}{ }^{2}\left(\mathrm{c}_{\mathrm{i}} \mathrm{y}_{\mathrm{i}}^{\mathrm{o}}+\mathrm{s}_{\mathrm{i}} \mathrm{z}_{\mathrm{i}}^{\mathrm{o}}\right)^{2}\right\}+\frac{\mathrm{b}_{\mathrm{i}}{ }^{3} \mathrm{t}_{\mathrm{i}}}{144}\left\{\mathrm{t}_{\mathrm{i}}{ }^{2}+12\left(\mathrm{~s}_{\mathrm{i}} \mathrm{y}_{\mathrm{i}}^{\mathrm{o}}-\mathrm{c}_{\mathrm{i}} \mathrm{z}_{\mathrm{i}}^{\mathrm{o}}\right)^{2}\right\} \\
& J=\sum_{i=1}^{n} \frac{b_{i} t_{i}^{3}}{3}
\end{aligned}
$$

in which,

$\mathrm{c}_{\mathrm{i}}=\cos \left(\rho_{\mathrm{i}}\right)$

$\mathrm{s}_{\mathrm{i}}=\sin \left(\rho_{\mathrm{i}}\right)$

and, 
$\mathrm{n} \quad$ : number of component plates

$\lambda_{i} \quad$ : warping constant of plate (i) determined from (12)-(13).

All other variables are geometric properties of plate (i), as shown in Fig. 5.

\section{A.2. Properties of Open Circular Cross-Section}

With reference to Fig. 12, and assuming small thickness in comparison with the section radius $(\mathrm{t}<<\mathrm{R})$, the following cross-sectional properties can be derived:

$$
\mathrm{A}=2 \operatorname{Rt} \alpha_{\mathrm{o}}
$$

$I_{y y}=\frac{R^{3} t}{2}\left(2 \alpha_{o}-\sin \left(2 \alpha_{o}\right)\right)$

$I_{z z}=\frac{R^{3} t}{2 \alpha_{o}}\left(-2+2 \alpha_{o}{ }^{2}+2 \cos \left(2 \alpha_{o}\right)+\alpha_{o}+\sin \left(2 \alpha_{o}\right)\right.$,

$I_{y \Phi}=R^{4} t\left(\sin \left(\alpha_{o}\right)\left(1+\frac{\sin \left(2 \alpha_{o}\right)}{2 \alpha_{o}}\right)-2 \alpha_{o} \cos \left(2 \alpha_{o}\right)\right)$

$I_{\Phi \Phi}=R^{5} t\left(\frac{2 \alpha_{o}^{3}}{3}-\frac{3 \sin ^{2}\left(\alpha_{0}\right)}{\alpha_{o}}+\sin \left(2 \alpha_{o}\right)\left(2-\frac{\sin ^{2}\left(\alpha_{o}\right)}{2 \alpha_{o}^{2}}\right)\right)$

$\mathrm{I}_{\mathrm{yz}}=\mathrm{I}_{\mathrm{z} \Phi}=0$

$\mathrm{J}=\frac{2 \mathrm{R} \alpha_{0} \mathrm{t}^{3}}{3}$

It can be also shown for any cross-section that the position of the shear centre with respect to the centroid is given by:

$$
\begin{aligned}
& \mathrm{y}_{\mathrm{s}}=-\frac{\mathrm{I}_{\mathrm{z} \Phi}}{\mathrm{I}_{\mathrm{zz}}} \\
& \mathrm{z}_{\mathrm{s}}=\frac{\mathrm{I}_{\mathrm{y} \Phi}}{\mathrm{I}_{\mathrm{yy}}}
\end{aligned}
$$




\section{NOTATION}

- Generic symbols of matrices and vectors are represented by bold font-type with left side subscripts or superscripts (e.g. ${ }_{s} G,{ }_{g}^{e} f$ ). This rule also applies to three-dimensional matrices.

- Subscripts and superscripts to the right side of the generic symbol indicate the term of the vector or matrix under consideration (e.g. ${ }_{s} G_{i, j, k},{ }_{g} f_{j}$ ).

\section{Operators}

o $\quad$ : right-side superscript, denotes initial values during an incremental step.

$\mathrm{T} \quad$ : right-side superscript, transpose sign.

$\delta \quad:$ incremental operator for variables, vectors and matrices.

a : partial differentiation.

$\sum_{\mathrm{i}} \quad$ : summation over range variable (i).

[ ] : encloses terms of a matrix.

〈〉 : encloses terms of a row vector.

\section{Symbols}

A : cross-sectional area

$b_{i} \quad$ : width of component plate (i)

E : elastic Young's modulus

$\mathrm{c}^{\mathrm{f}} \quad$ : local element forces

${ }_{\mathrm{g}}^{\mathrm{e}} \mathrm{f} \quad$ : global forces of element (e) 


\begin{tabular}{|c|c|}
\hline G & shear modulus \\
\hline${ }_{\mathrm{s}} \mathrm{G}$ & geometric stiffness matrix \\
\hline $\mathrm{I}_{\# *}$ & cross-sectional properties defined in (18) \\
\hline $\mathrm{J}$ & St. Venant's torsional constant \\
\hline $\mathrm{c}^{\mathrm{k}}$ & local element tangent stiffness matrix \\
\hline $\mathrm{g} \mathrm{k}$ & global element tangent stiffness matrix \\
\hline $\mathrm{L}$ & element length \\
\hline $\mathrm{n}$ & number of component plates within a cross-section \\
\hline$P$ & global applied forces \\
\hline$t_{i}$ & thickness of component plate (i) \\
\hline $\mathrm{T}$ & transformation matrix from local to global forces \\
\hline u & cross-sectional displacement in local $\mathrm{x}$-direction \\
\hline$u_{\mathrm{g}}$ & reference line displacement in local $\mathrm{x}$-direction \\
\hline${ }_{\mathrm{c}} \mathrm{u}$ & local element displacements, including ${ }_{\mathrm{c}}^{\mathrm{b}} \mathrm{u}$ and ${ }_{\mathrm{c}}^{\mathrm{w}} \mathrm{u}$ \\
\hline
\end{tabular}

$$
\left\{\begin{array}{lllllllll}
\theta_{1 \mathrm{y}} & \theta_{1 \mathrm{z}} & \theta_{2 \mathrm{y}} & \theta_{2 \mathrm{z}} & \Delta & \theta_{\mathrm{T}} & \theta_{1}^{\prime} & \theta_{2}^{\prime}
\end{array}\right\}^{\mathrm{T}}
$$

${ }_{\mathrm{g}} \mathrm{u} \quad$ : global element displacements, including ${ }_{\mathrm{g}}^{\mathrm{b}} \mathrm{u}$ and ${ }_{\mathrm{g}}^{\mathrm{w}} \mathrm{u}$

$$
\left\{\begin{array}{llllllllllllll}
\mathrm{u}_{1} & \mathrm{v}_{1} & \mathrm{w}_{1} & \alpha_{1} & \beta_{1} & \gamma_{1} & \mathrm{u}_{2} & \mathrm{v}_{2} & \mathrm{w}_{2} & \alpha_{2} & \beta_{2} & \gamma_{2} & i \chi_{1} & \chi_{2}
\end{array}\right\}^{\mathrm{T}}
$$

U : global structural displacements

${ }^{\mathrm{e}} \mathrm{U} \quad$ : strain energy of element (e) 
: cross-sectional displacement in local y-direction

$\mathrm{v}_{\mathrm{g}} \quad$ : reference line displacement in local $\mathrm{y}$-direction

$\mathrm{W}$

: cross-sectional displacement in local z-direction

$\mathrm{w}_{\mathrm{g}} \quad$ : reference line displacement in local z-direction

$\mathrm{y}_{\mathrm{i}}, \mathrm{z}_{\mathrm{i}} \quad$ : local coordinates for component plate (i)

$\mathrm{y}_{\mathrm{i}}^{\mathrm{o}}, \mathrm{z}_{\mathrm{i}}^{\mathrm{o}} \quad$ : origin of component plate (i)

$\alpha_{\mathrm{g}} \quad:$ reference line twist rotation

$\varepsilon_{\mathrm{x}} \quad:$ direct strain

$\Phi(\mathrm{y}, \mathrm{z}) \quad$ : warping function of cross-section

$\gamma \quad:$ Chwalla's constant

$\gamma_{\mathrm{xy}}, \gamma_{\mathrm{xz}} \quad:$ shear strains

$\lambda_{\mathrm{i}} \quad$ : warping constant for component plate (i)

$\rho_{\mathrm{i}} \quad$ : angle of component plate (i) 


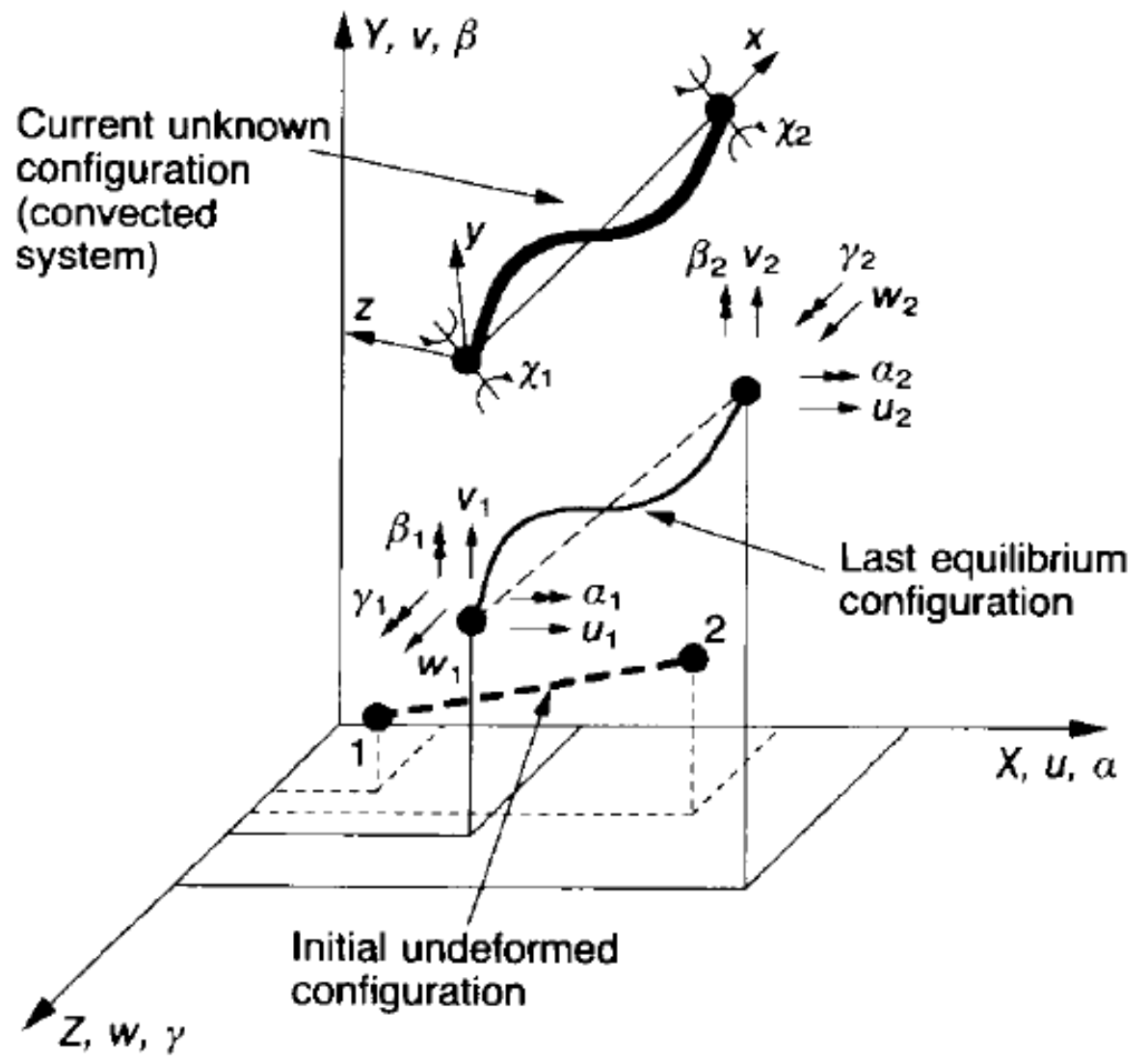

Figure 1. Eulerian (convected) system in relation to global reference system 


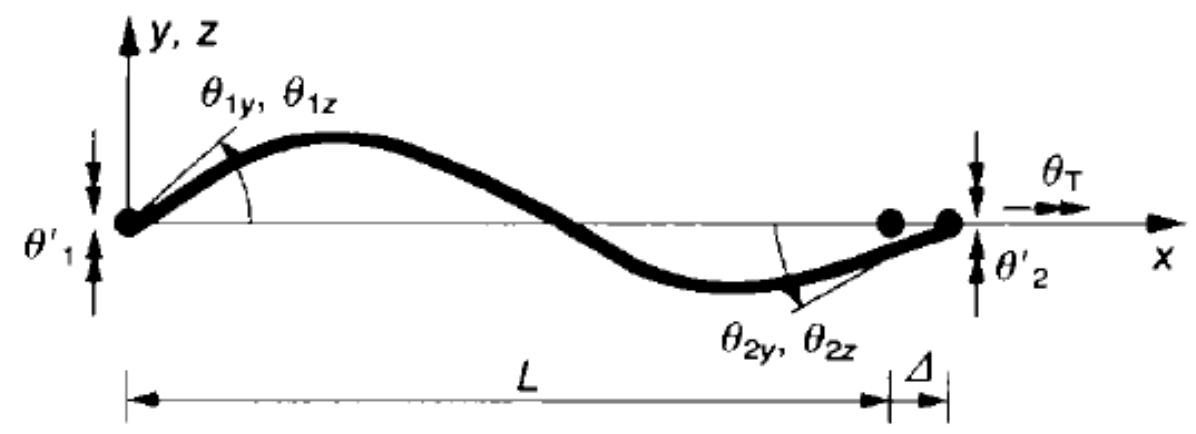

Figure 2. Local Eulerian displacements 

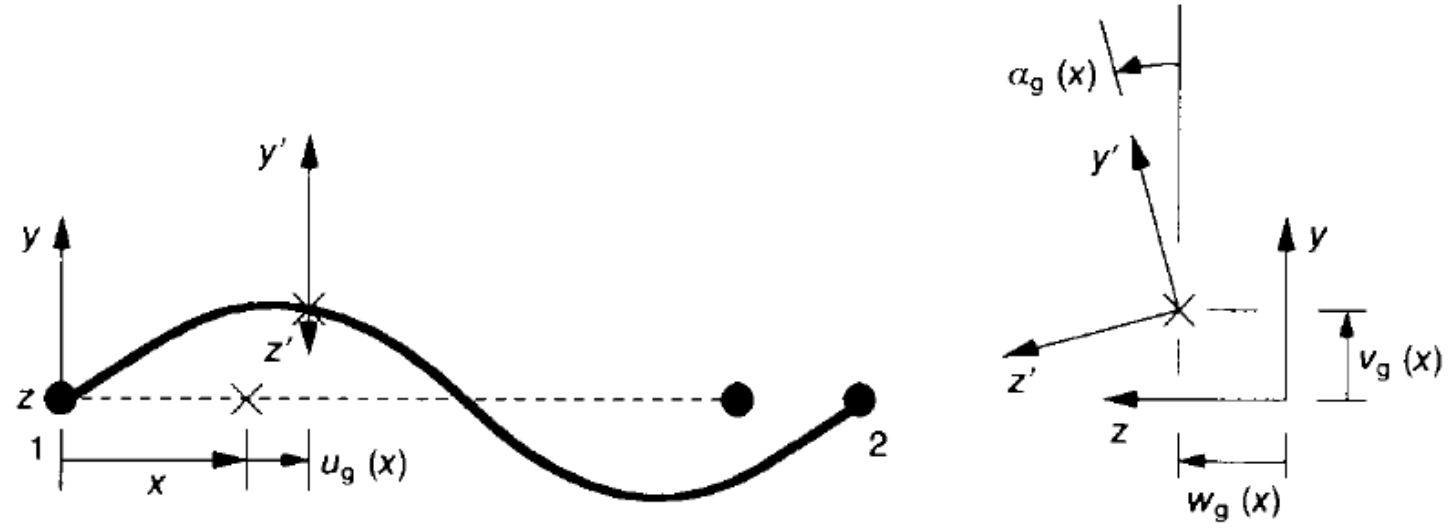

Figure 3. Reference line displacements in Eulerian system 


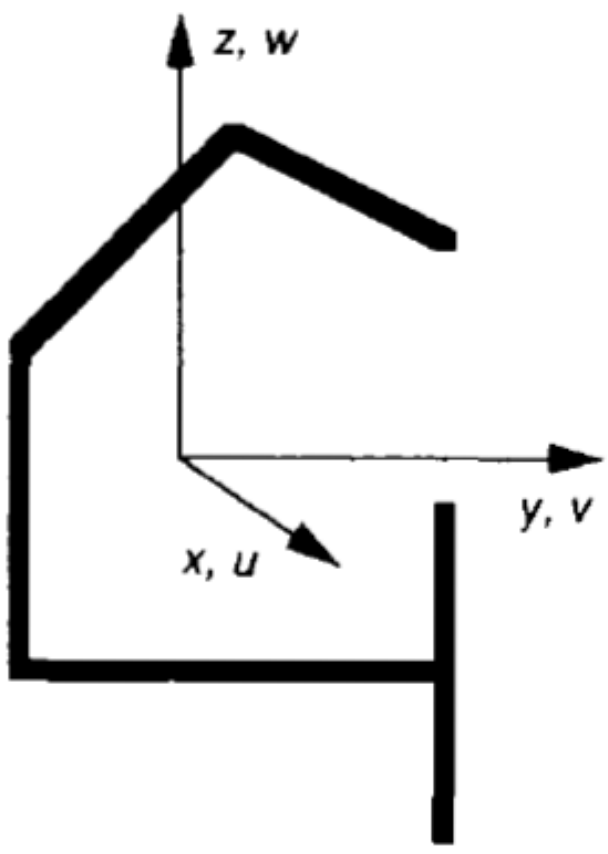

Figure 4. General thin-walled open cross-section 


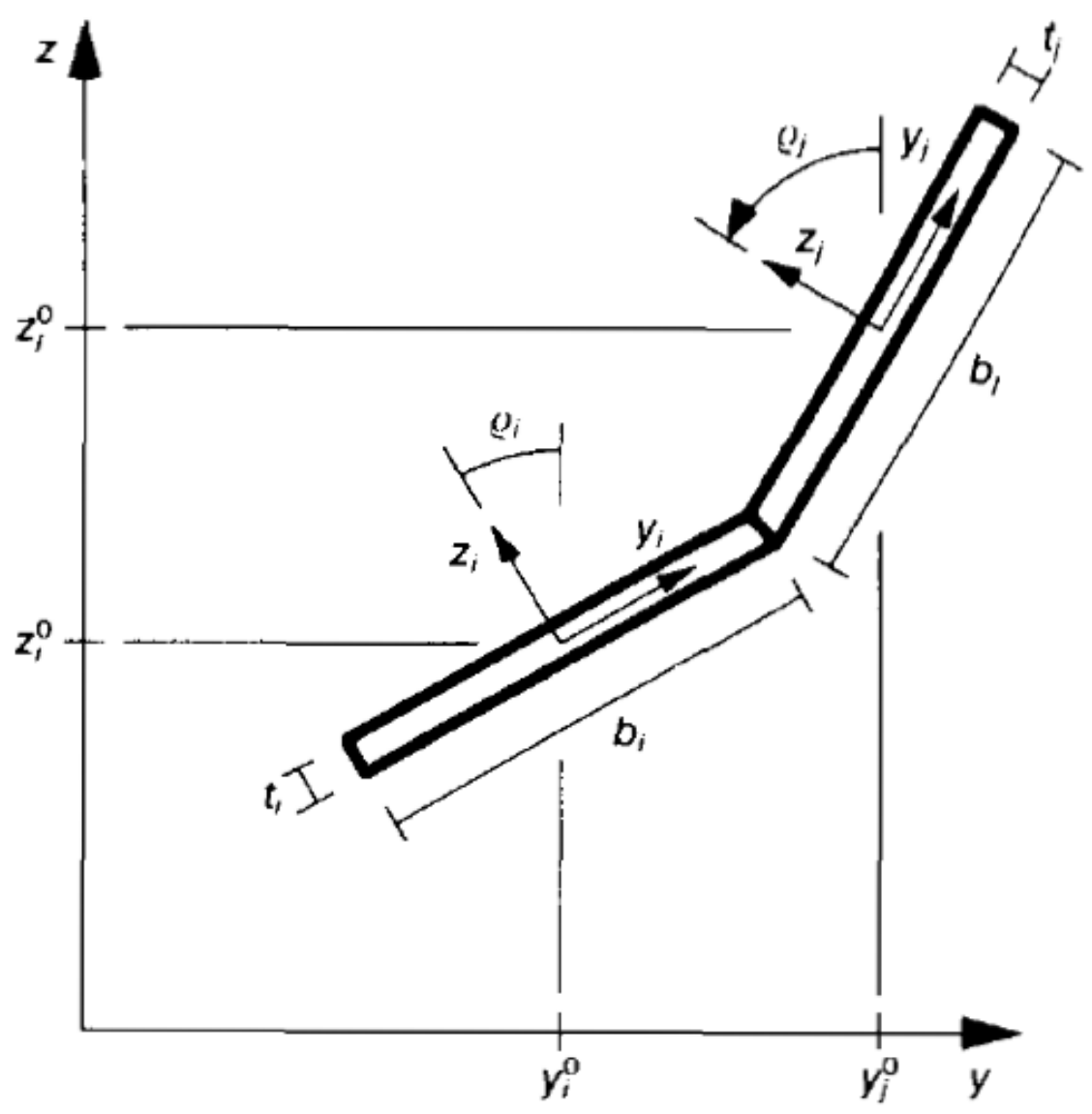

Figure 5. Component plates in an open cross-section 


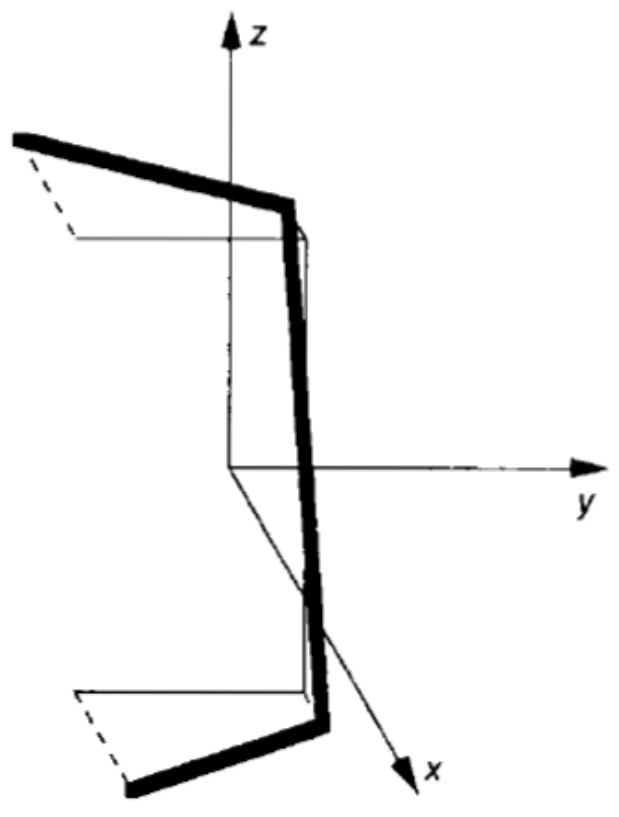

(a)

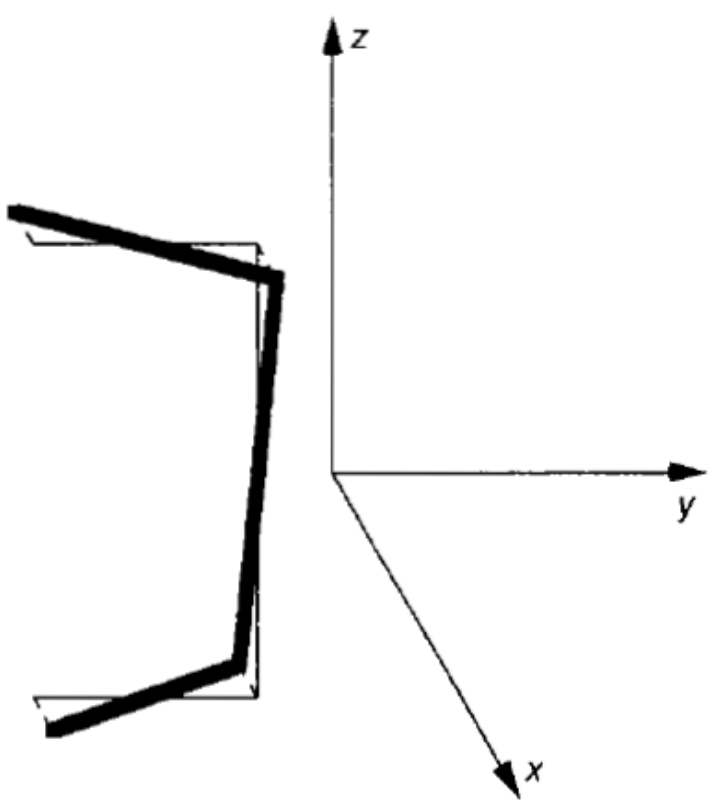

(b)

Figure 6. Warping deformation of channel section:

a) about centroid; b) about shear centre 
24 basic freedoms

4 warping freedoms

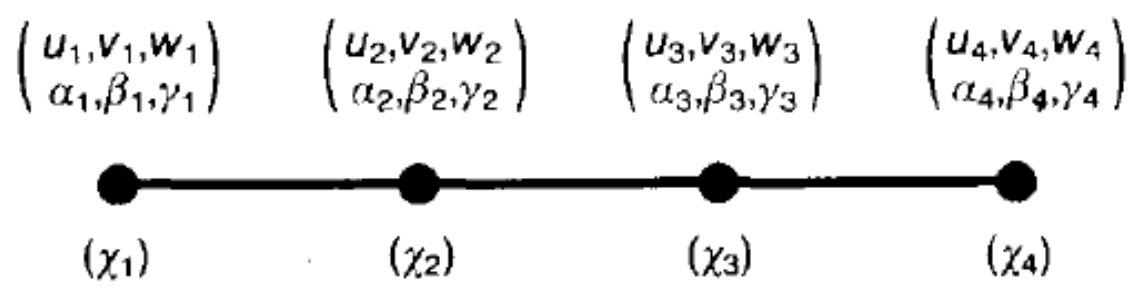

(a)

24 basic freedoms

6 warping freedoms

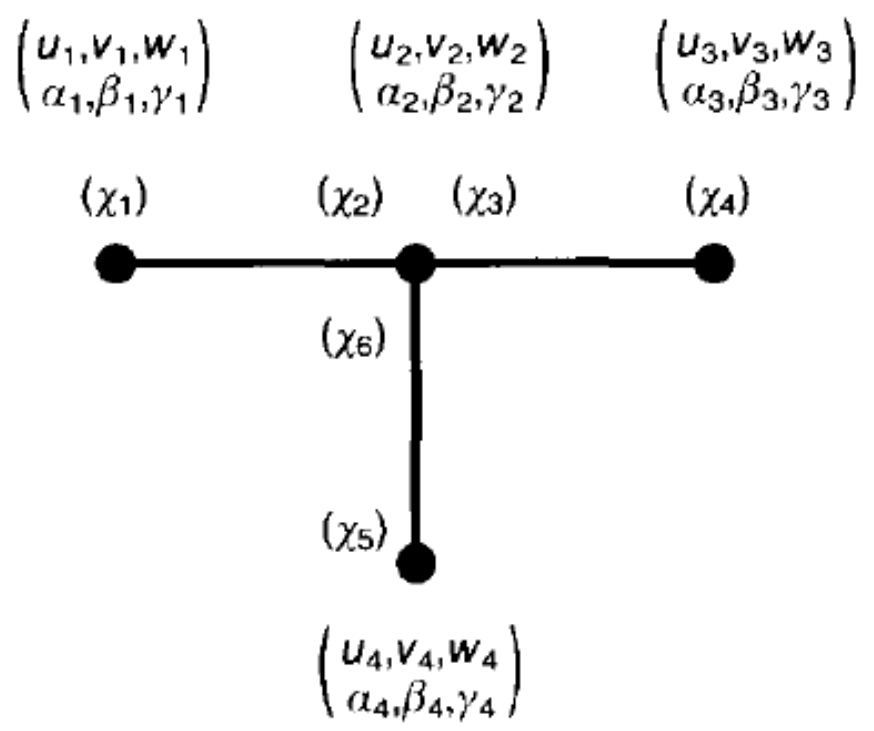

(b)

Figure 7. Global freedoms of thin-walled structural systems:

a) thin-walled beam; b) intersecting thin-walled members 
Flanges: $0.263 \times 0.0284 \mathrm{~m}^{2} \quad$ Web: $0.225 \times 0.0173 \mathrm{~m}^{2}$
$E=200 \times 10^{9} \mathrm{~N} / \mathrm{m}^{2}$
$y=0.3$

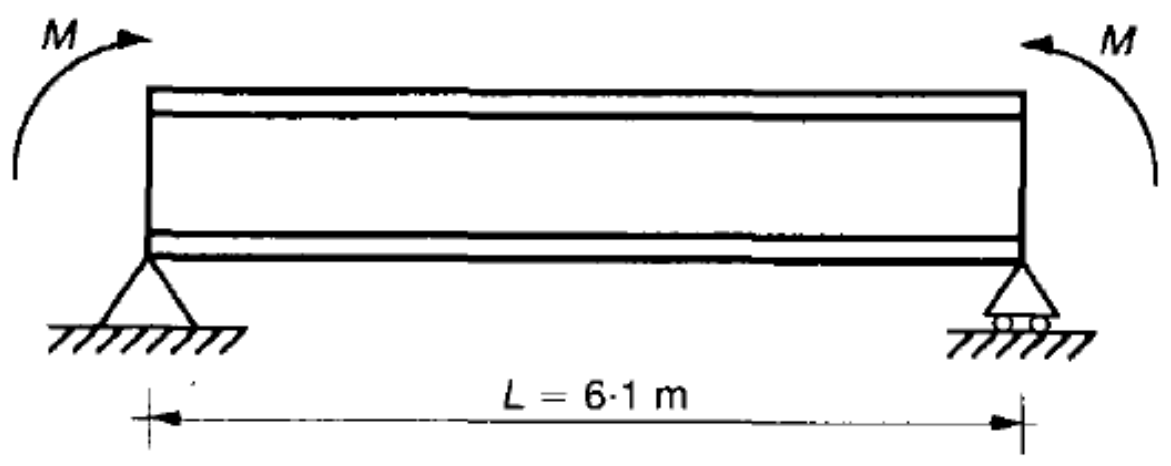

Figure 8. I-beam subject to end moments 


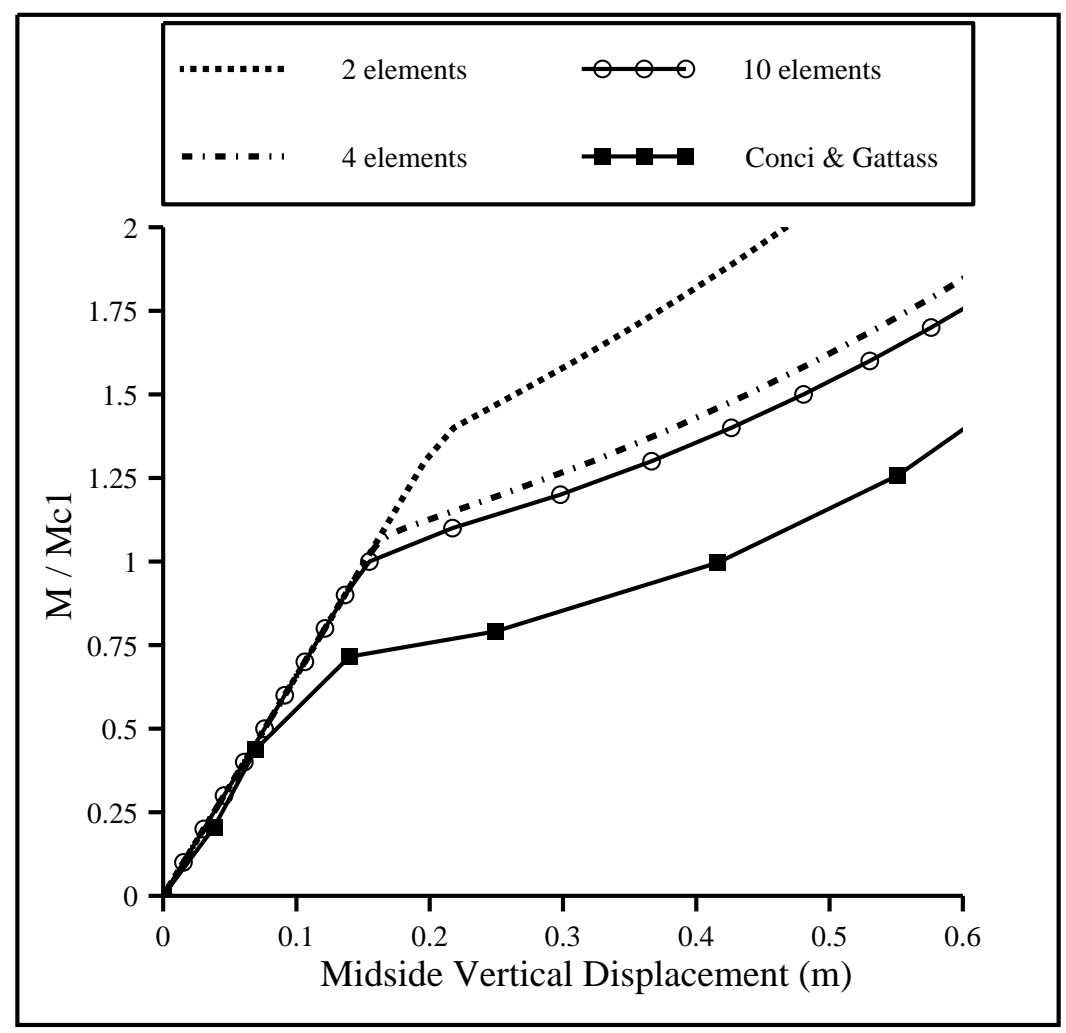

Figure 9. Vertical displacement of I-beam with free warping 


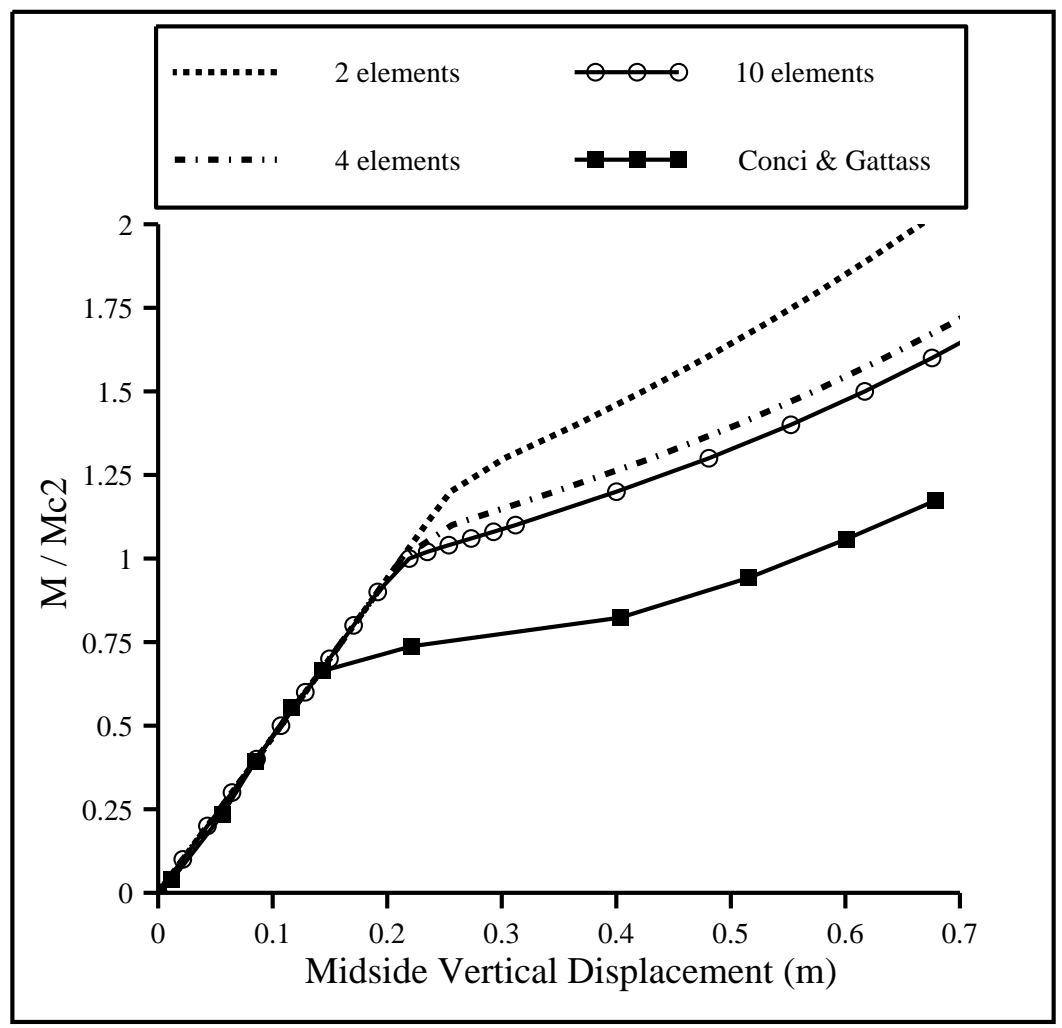

Figure 10. Vertical displacement of I-beam with restrained warping 


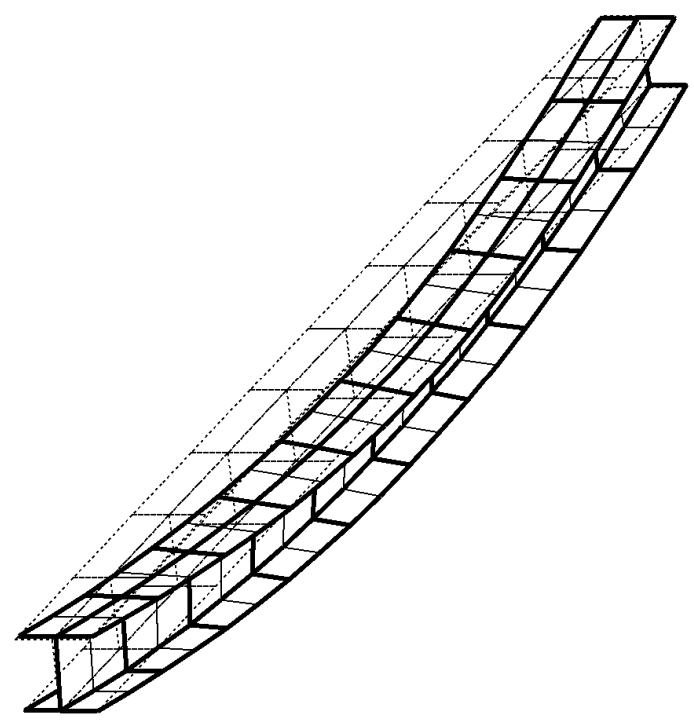

(a) Onset of buckling

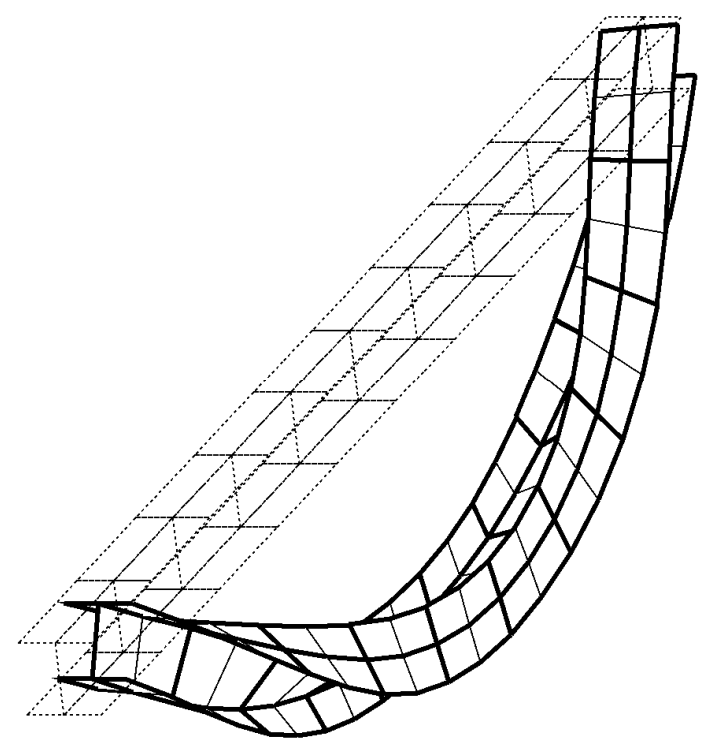

(b) Post-buckling

Figure 11. Deflected Shapes of I-beam 


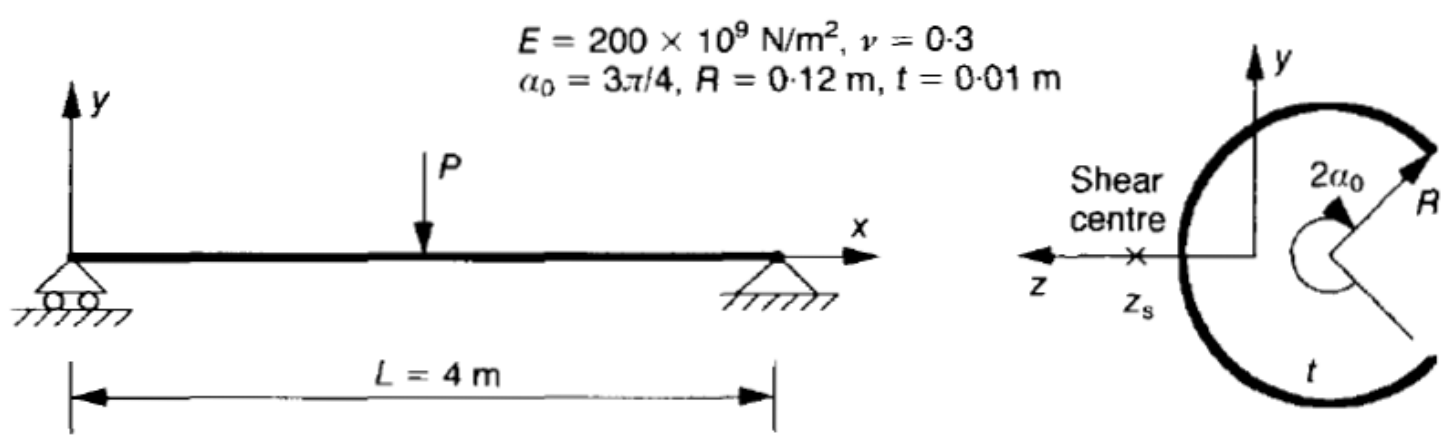

Figure 12. Geometric configuration and loading of C-beam 


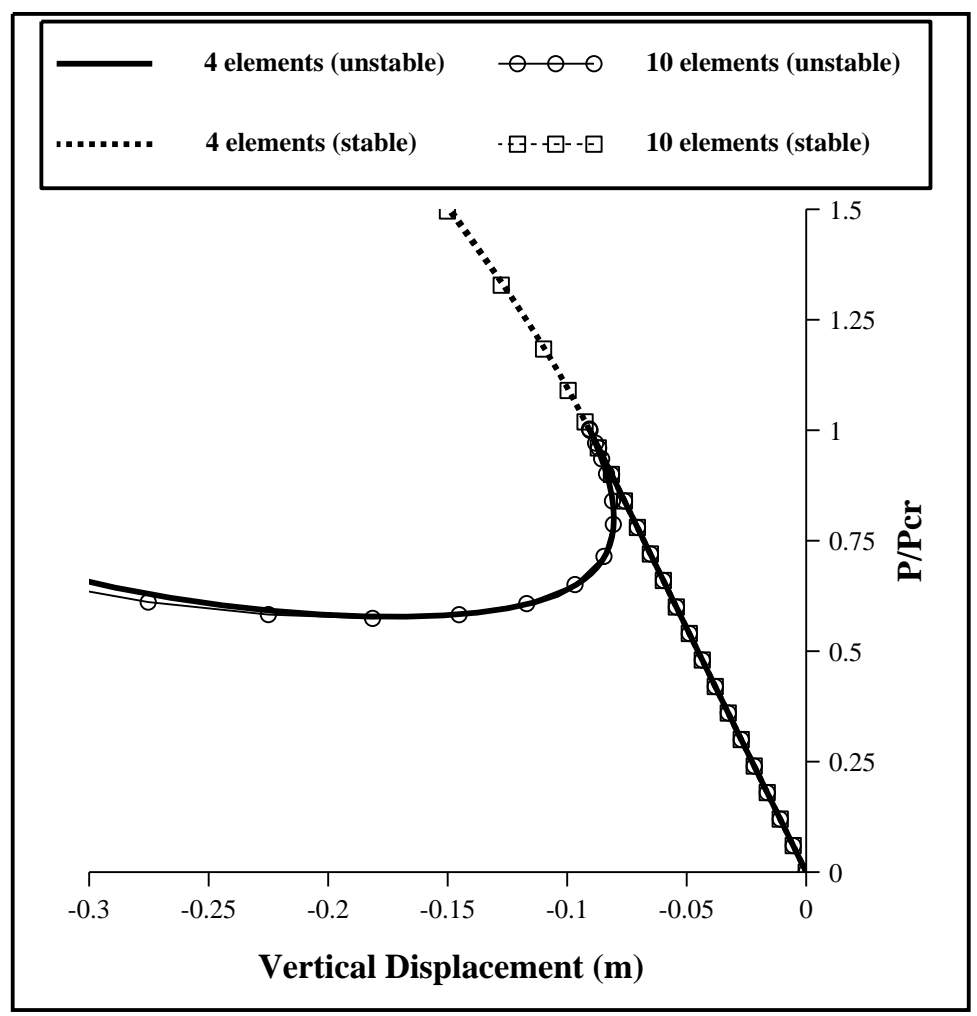

(a) Vertical

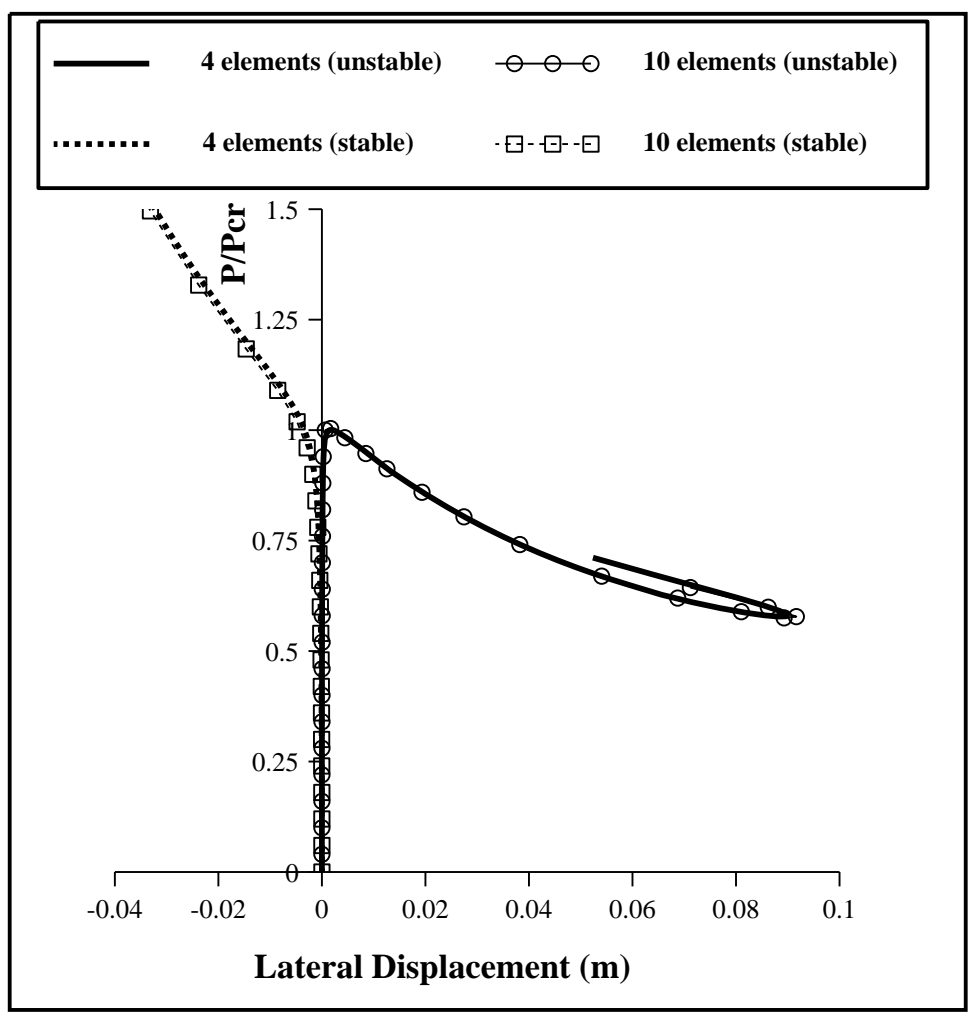

(b) Lateral

Figure 13. Midside displacemet of C-beam 


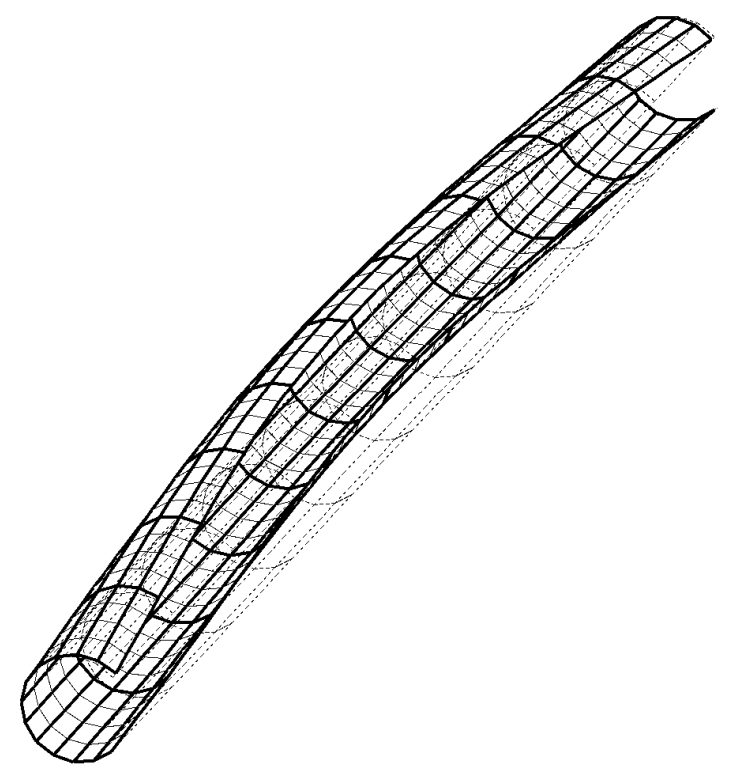

(a) Post-buckling shape

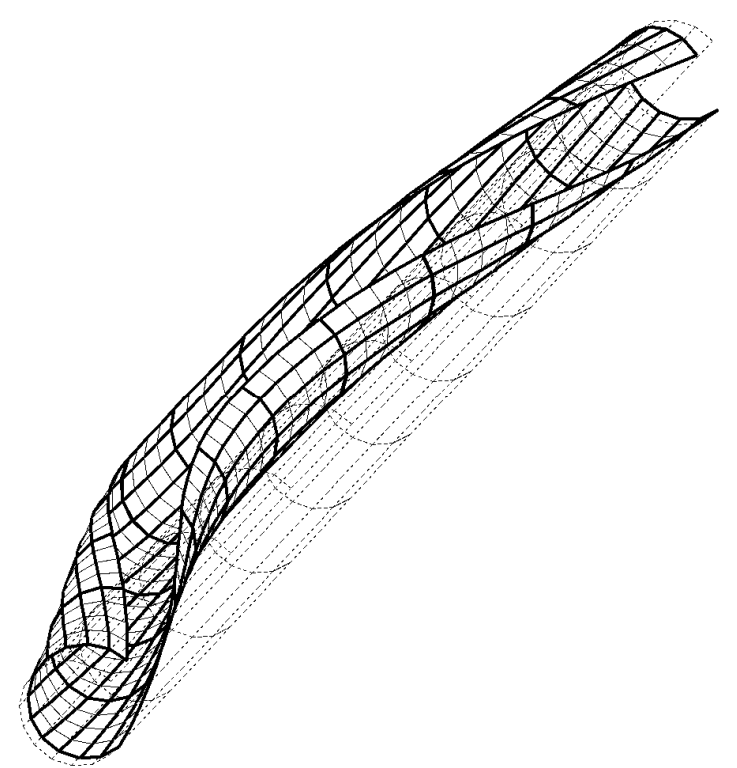

(b) Final shape

Figure 14. Deflected shapes of C-beam (unstable case) 


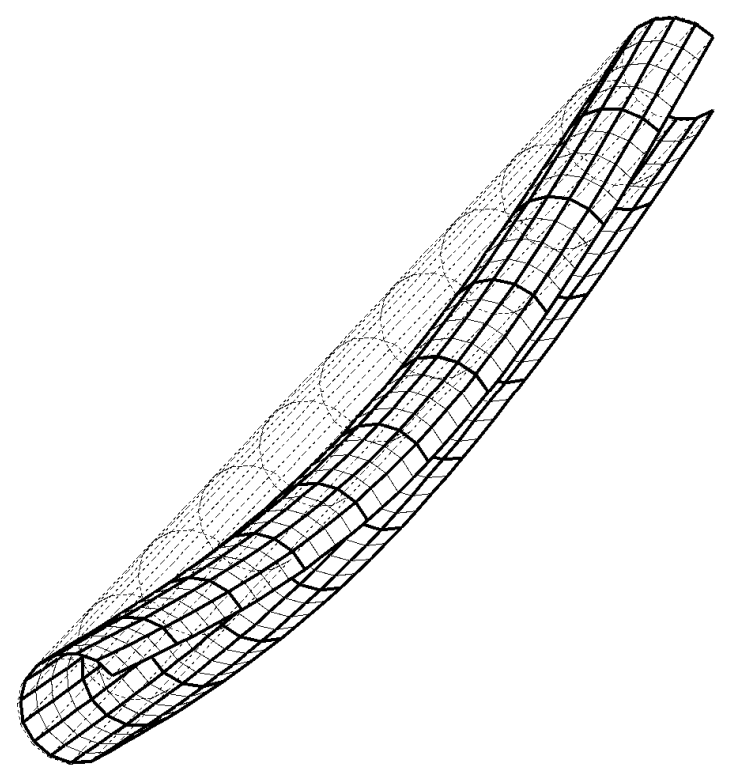

(a) Post-buckling shape

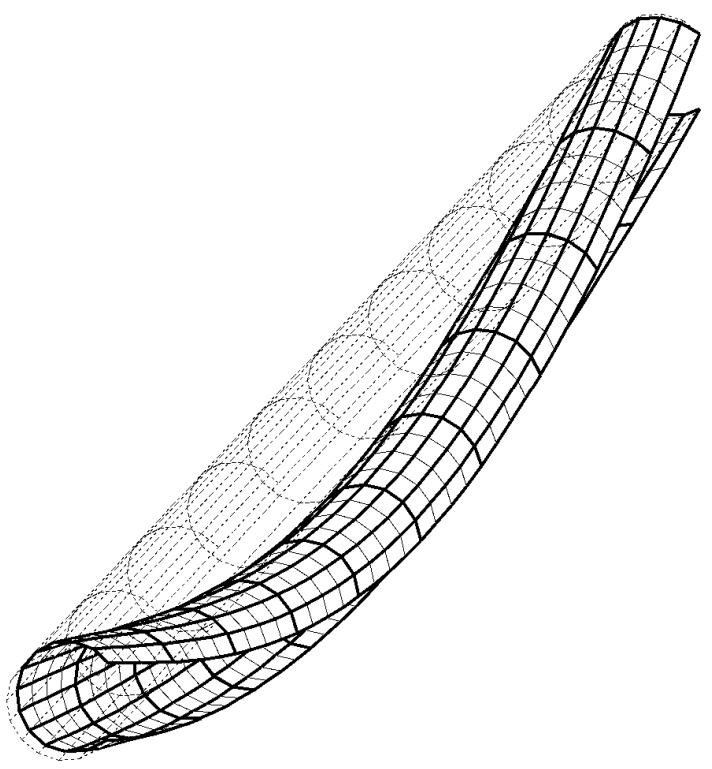

(b) Final shape

Figure 15. Deflected shapes of C-beam (stable case) 


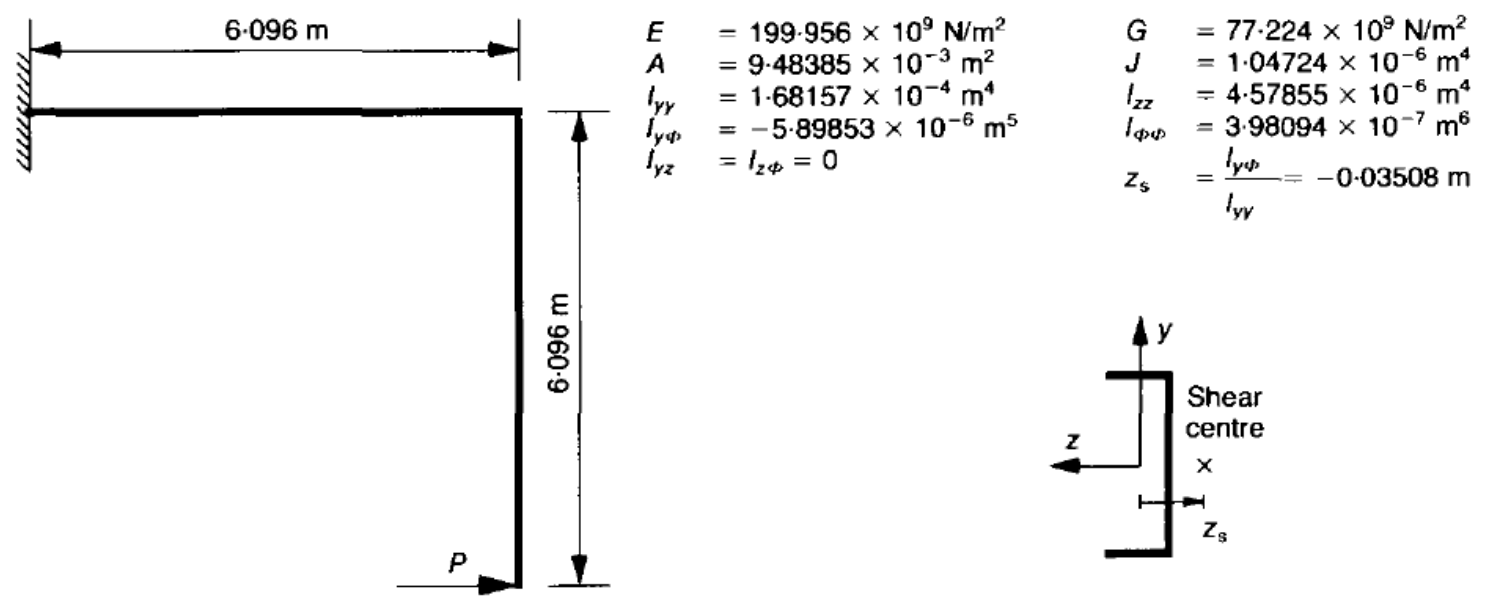

Figure 16. Geometric configuration and loading of L-frame 


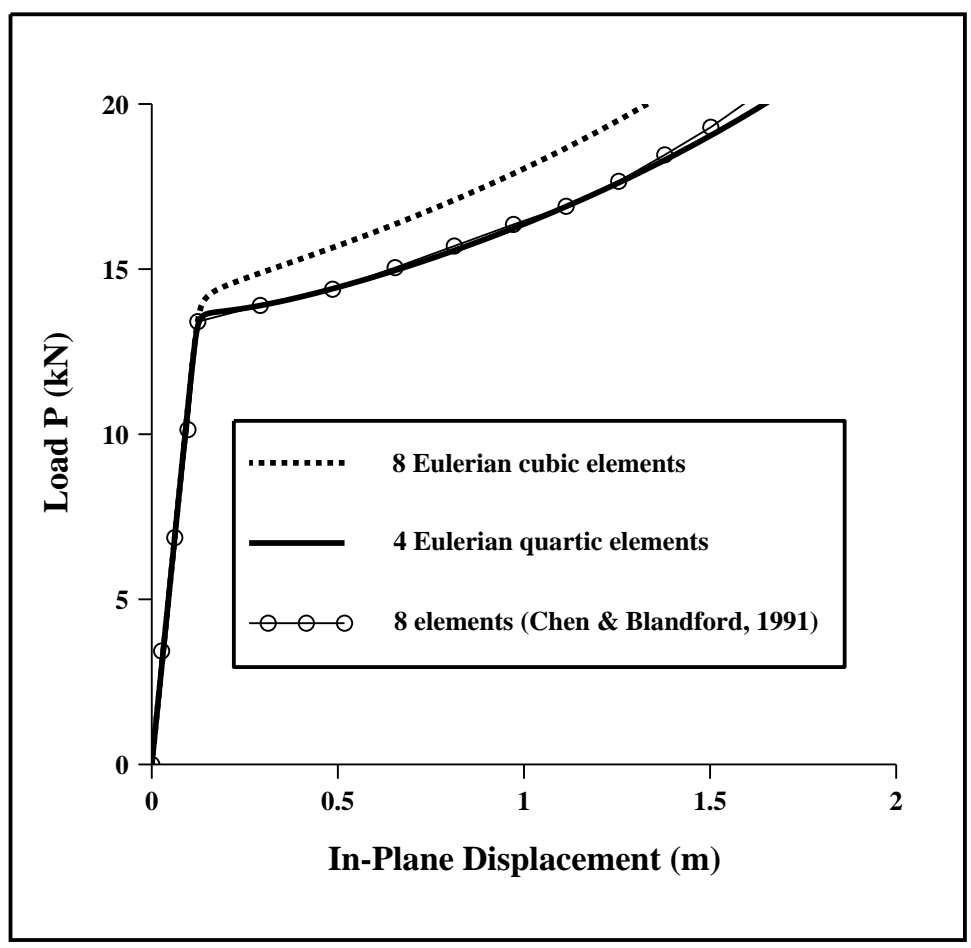

(a) In-plane

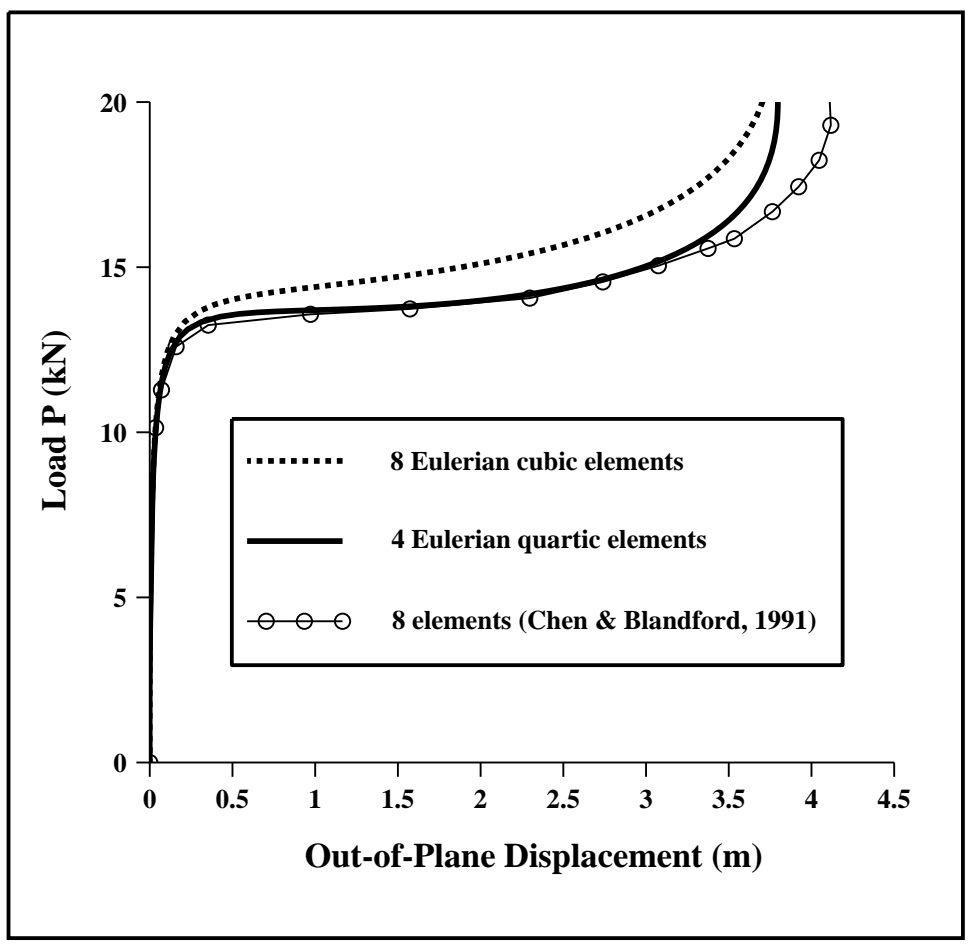

(b) Out-of-plane

Figure 17. Displacements of L-frame

Izzuddin: An Eulerian Approach to the Large Displacement Analysis of Thin-Walled Frames 


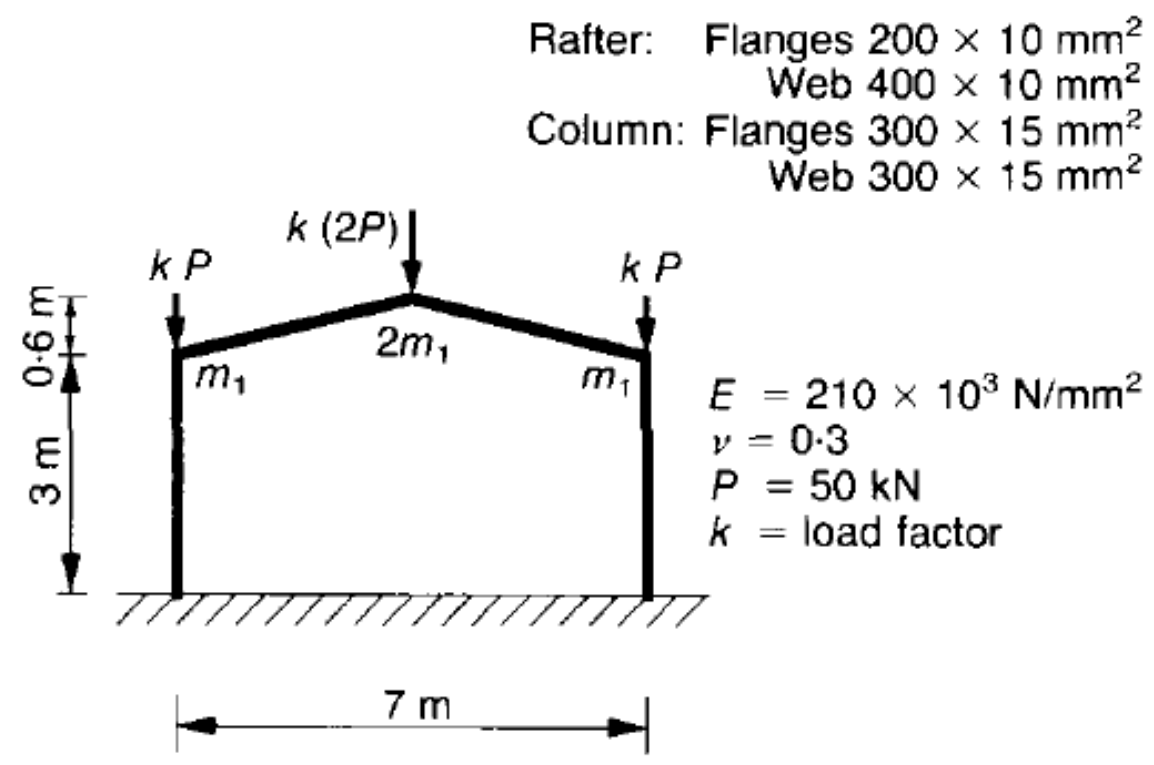

Figure 18. Geometric configuration and loading of portal frame 


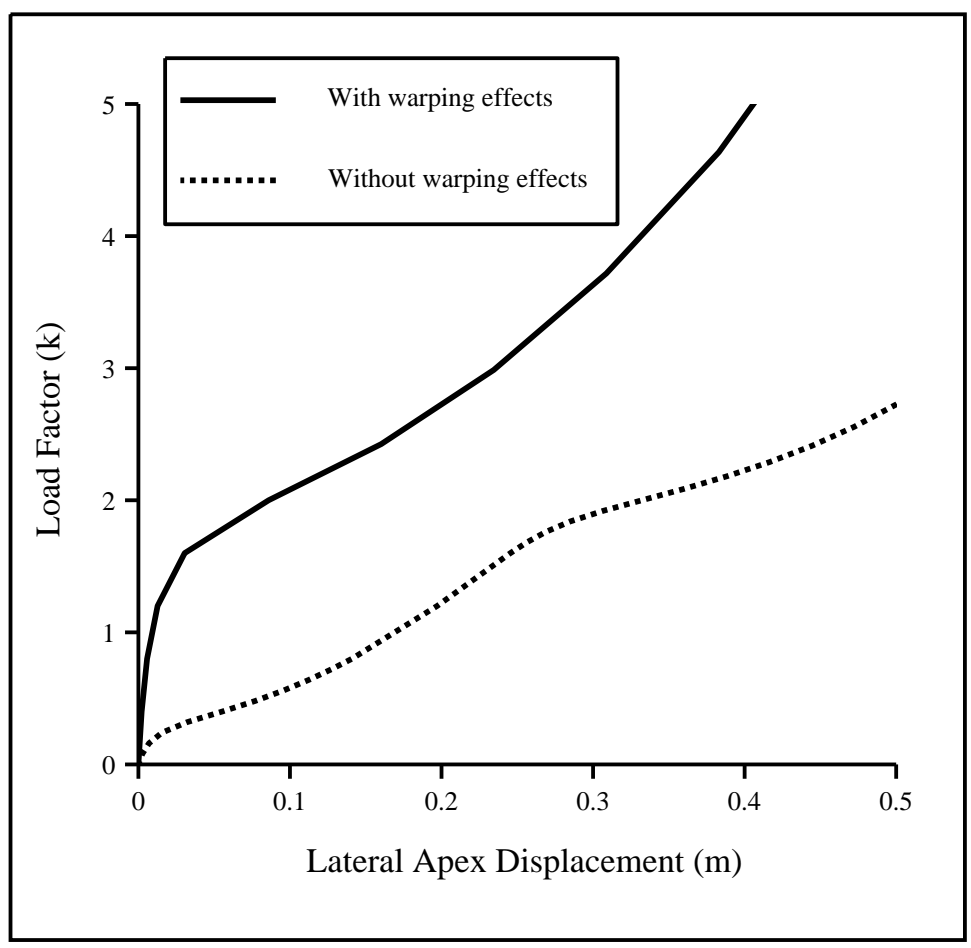

(a) Lateral displacement

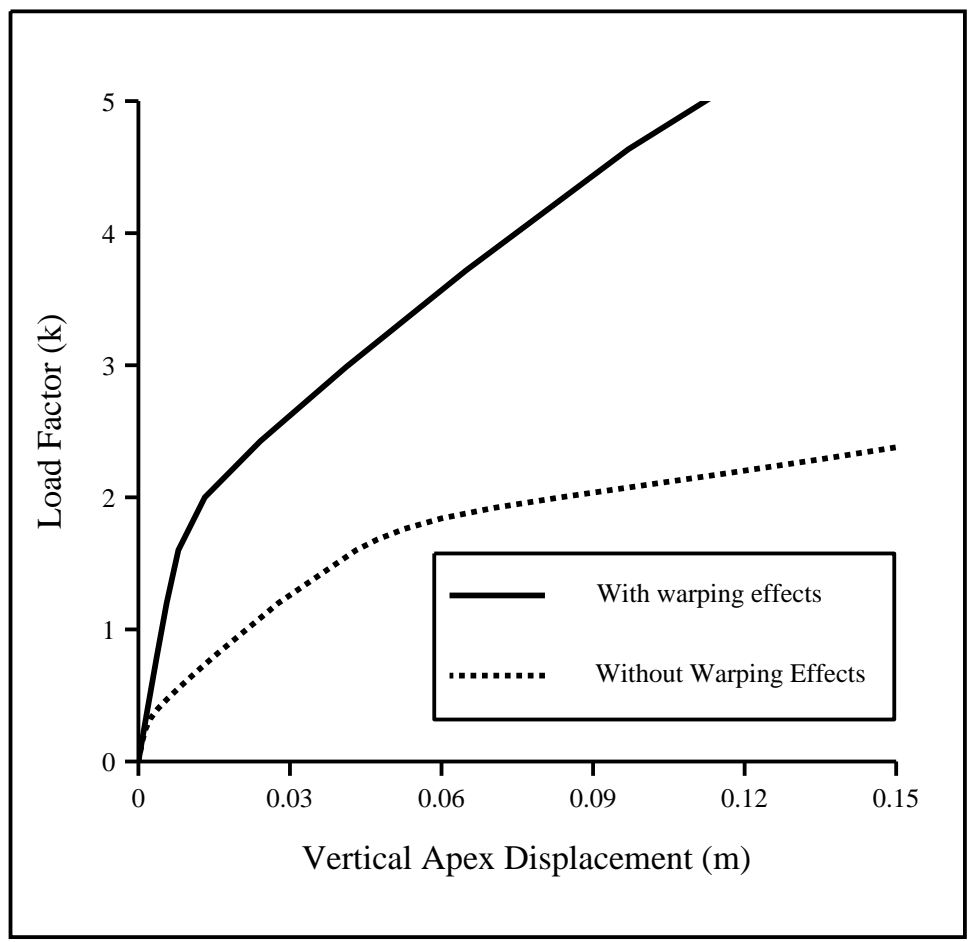

(b) Vertical displacement

Figure 19. Apex displacements of portal frame 


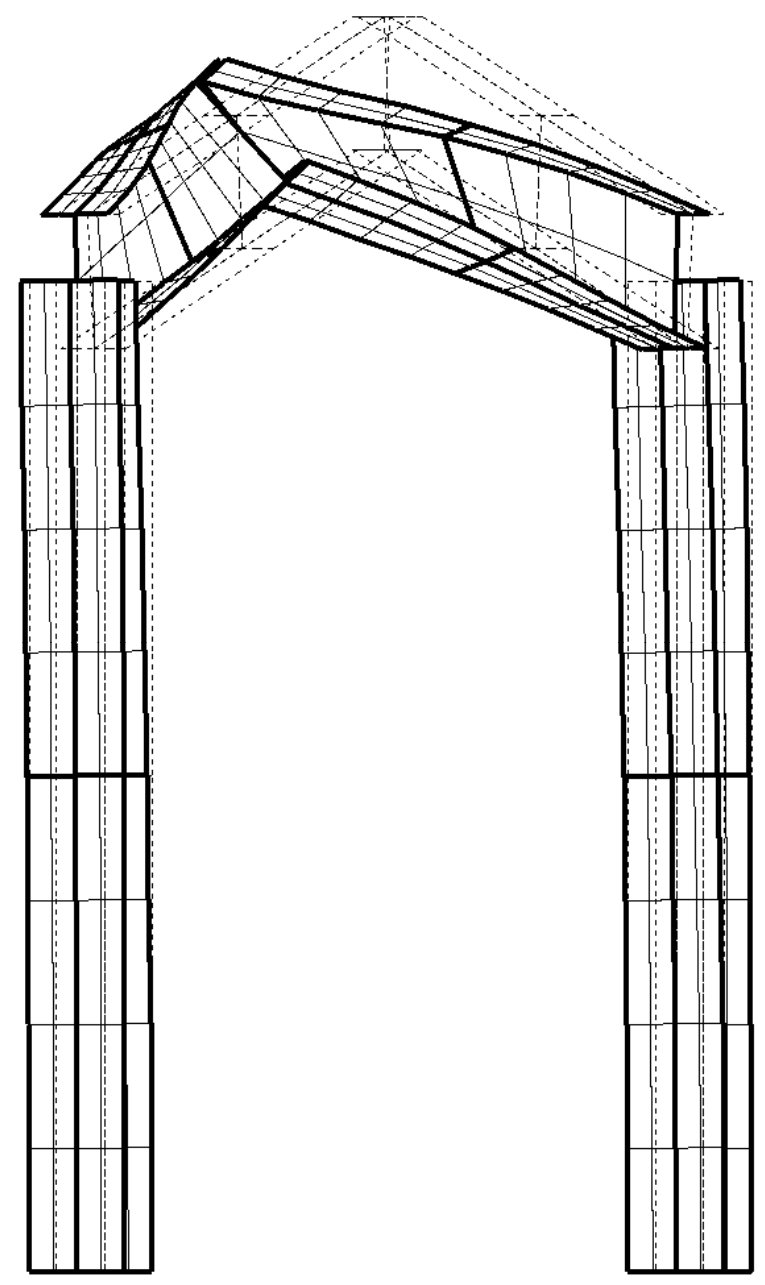

Figure 20. Final deflected shape of portal frame 